\title{
Changes in Shear Moduli of Liquefied and Nonliquefied Soils during the 1995 Kobe Earthquake and Its Aftershocks at Three Vertical-Array Sites
}

\author{
by Olga Pavlenko and Kojiro Irikura
}

\begin{abstract}
Acceleration records of the 1995 Kobe earthquake and its first aftershocks, provided by vertical arrays at Port Island (PI), SGK, and TKS sites, were used to estimate changes in the shear moduli of subsurface soils caused by strong ground motion. Shear-moduli estimates are based on stress-strain relations determined for consecutive time intervals during the mainshock and aftershocks. We found that in the upper $0-13 \mathrm{~m}$ at PI (reclaimed fill above the groundwater level), the shear modulus decreased by $\sim 80 \%-90 \%$ of its initial value owing to liquefaction. Signs of its recovery appeared 3-5 min after the decrease in the intensity of strong motion. At depths of 13-18 m (reclaimed fill below the water level) and 27-32.5 m (water-saturated sand) at PI, 0-11 m at SGK, and 0-14 $\mathrm{m}$ at TKS (water-saturated alluvium), the shear modulus decrease was estimated at about $\sim 80 \%, 50 \%-60 \%$, $60 \%-70 \%$, and $\sim 50 \%$, respectively. Recovery began immediately after the decrease in the intensity of strong motion and was completed within a few minutes. The results show that the behavior of the upper layers at sites PI and SGK, where the highest accelerations were recorded, was dynamically unstable. So far as the method can be applied to any site where vertical-array records and profiling data are available, accumulation of representative data on nonlinear soil behavior during strong motion for various soil conditions is desirable. Summarizing and generalizing these data, we may be able to predict soil behavior in future earthquakes.
\end{abstract}

\section{Introduction}

Although studies concerning the dynamic properties of soils date back several decades, they came to a qualitatively new experimental level during the 1960s-1970s after the catastrophic earthquakes in 1964 in Niigata (Japan) and Anchorage (Alaska). These earthquakes were most destructive and accompanied by extensive liquefaction of watersaturated, sandy soils. Another strong earthquake that occurred in 1971 in California greatly damaged the San Fernando dam. After these events, dynamic testing of soils became of priority importance, and a breakthrough was made by Professor Seed of Berkeley University and his group (Seed and Lee, 1966). Their work initiated a wide study of liquefaction phenomena in sandy soils (Casagrande, 1975; Castro, 1975; Ishihara et al., 1975). For reliable calculation of the vibration of structures based on soil layers, dynamic (elastic, filtering, and damping) characteristics of soils were studied, and dynamic stability of soils was estimated. In particular, changes in their properties under dynamic loading were investigated, such as elastic-moduli degradation, increase in deformability, and decrease in rigidity.

The problem of the estimation of dynamic instability of soils (i.e., a higher probability of the deformability increase and shear-modulus decrease in soils under dynamic, rather than static, loading [Voznesensky, 1994]) is urgent. The examples of recent, destructive earthquakes (Spitak, 1988; Loma Prieta, 1989; Northridge, 1994; Kobe, 1995; Neftegorsk, 1995; Taiwan, 1999; and Gujarat, 2001) show that damage to buildings and structures is high, and thus, more reliable and adequate estimates of stability of ground basements under dynamic loading are required.

Among recent methods of soil testing, laboratory dynamic methods are most diverse and numerous. The main problem in laboratory testing is to create adequate dynamic loading on a soil sample with the help of a laboratory installation. However, it seems to be impossible in principle to create adequate loading (Lee, 1976). Among field methods, the geotechnical field methods, which aim at an estimation of soil rigidity under conditions of dynamic loading, such as penetration methods, dynamic sounding, pile testing, and so forth, seem to be more promising compared with the seismoacoustic and vibration methods. Great success has been achieved in this field, and extensive data have been accumulated concerning the behavior of cohesive and cohesionless soils under loadings of various intensities.

Nonetheless, disagreement remains between the in situ conditions of dynamic loading on soils in earthquakes and 
their laboratory and field-experimental substitutes. Soils have been found to be such complex, natural, multicomponent systems that not only do they change the parameters of propagating seismic waves but also they are changed themselves. These phenomena are inseparable; they are rather complicated and connected with the movement of underground water. Therefore, any data on soil behavior during strong ground motion and on the elastic moduli of soils obtained in situ are of particular importance. In situ variations of the shear modulus from one observational point to another can be evaluated by the standard spectral ratio and horizontalto-vertical spectral ratio techniques (Beresnev and Wen, 1996; Dimitriu et al., 2000, 2001). However, since the spectra are calculated over long intervals of accelerograms, the results are smoothed and do not allow determination of the shear-modulus variations during strong motion. Such information can be obtained from vertical-array records of strong motion (Pavlenko and Irikura, 2001a, b). Seismic vertical arrays provide valuable data on soil behavior at different depths during strong ground motion.

Vertical-array records of the 1995 Kobe earthquake undoubtedly testified to the soil nonlinearity at many recording sites (Sato et al., 1996; Yasuda et al., 1996; Aguirre and Irikura, 1997; Ishihara et al., 1998; Kazama et al., 1998; Kokusho and Matsumoto, 1998; Soeda et al., 1999; Pavlenko and Irikura, 2001a, b). Methods of backcalculation, multireflection analysis, and inversion of records of the 1995 Kobe earthquake at Port Island (PI), SGK, TKS, and KNK vertical-array sites were used to estimate the optimum values of $S$-wave velocity $\left(V_{s}\right)$ and damping ratio in sedimentary layers during the mainshock and an aftershock (Sato et al., 1996). The optimized values of $V_{s}$ during the mainshock were found to be smaller than their initial values obtained by the $P S$-wave logging, especially for the upper liquefied layer at PI. To trace the development of liquefaction, the records at PI were divided into two parts, and it was found that liquefaction was still developing after the first period, 4.1-9.22 sec. Analysis of an aftershock with a maximum surface acceleration of $\sim 10 \mathrm{gal}\left(\mathrm{cm} / \mathrm{sec}^{2}\right)$ at PI, which occurred 2 min after the mainshock, showed that $V_{s}$ for Pleistocene and Holocene layers underlying the reclaimed fill had returned to their initial values, while $V_{s}$ in the fill layer had almost the same reduced values as in the mainshock, indicating that the fill was still under a liquefied condition (Sato et al., 1996). However, the computed horizontal acceleration was slightly different from the observed values and quite different at the level of GL-25 $\mathrm{m}$ for site TKS. Hence, it was difficult to simulate nonlinear seismic amplification by using multireflection analysis with optimized properties for a longduration time history, including completely different types of waves at site TKS (Sato et al., 1996).

The work was continued by Kokusho and Matsumoto (1998). Maximum acceleration and maximum shear strain were estimated as a function of depth. A clear strain dependency was found in the backcalculated shear modulus and damping, which is consistent with the laboratory test results for each kind of considered soil. It was concluded that further study was needed for a better estimation of nonlinear response during strong earthquakes.

The seismic behavior of an alluvial clay layer underlying reclaimed soil at PI was studied by Kazama et al. (1998). The shear stress-strain relationship of the clay layer was estimated from the mainshock by calculating separately the shear-strain and shear-stress evolution from filtered $(f \leq 1.2$ $\mathrm{Hz}$ ) acceleration records above (GL-16 $\mathrm{m}$ ) and below (GL$32 \mathrm{~m}$ ) the clay layer. Stress-strain relations corresponding to low-frequency components were estimated for six successive time intervals within $\sim 10 \mathrm{sec}$ of strong motion.

However, strong-motion records by vertical arrays provide us with all the necessary information to reconstruct stress-strain relations in situ, from the surface down to the location of the deepest recording device (Pavlenko and Irikura, 2002a). The obtained stress-strain relations describe in detail soil behavior during strong motion and allow further study of the qualitative and quantitative characteristics of elastic nonlinearity of soils in different layers (Pavlenko and Irikura, 2002b).

To determine the stress-strain relations in layers from the surface down to the location of the deepest device, the propagation of a vertically incident seismic $S$ wave in the horizontally layered sediments is calculated. Assumptions based on the profiling data are made about types of stressstrain relations in different layers, and sets of various stressstrain curves are generated. Item-by item examination is then applied to find groups of curves that show the best-fit approximation between the observed and simulated records.

As an example, records of the 1995 Kobe earthquake provided by vertical arrays at PI, SGK, and TKS sites were used to estimate the stress-strain relations in soils. A good agreement was obtained between the observed and simulated records, and a better understanding of processes occurring in soils during strong motion was achieved (Pavlenko and Irikura, 2001a). It was shown that during the mainshock, the most significant (among the three studied sites) temporal changes in soil behavior took place at sites PI and SGK, where the strongest accelerations were recorded $(\sim 600 \mathrm{gal}$ at $-83 \mathrm{~m}$ and $\sim 340 \mathrm{gal}$ on the surface at PI, and $\sim 300$ gal at $97 \mathrm{~m}$ and $\sim 650 \mathrm{gal}$ on the surface at SGK). The obtained stress-strain relations were found to vary with time at these sites in surface layers ( 0 to $10-14 \mathrm{~m}$ ) but remained stable in deeper parts. At PI, a progressive reduction of the shear modulus in the upper layers $(0-13 \mathrm{~m})$ due to liquefaction can be traced by stress-strain relations changing with time. At the TKS site, the acceleration level was lower (less than $\sim 100$ gal at $100 \mathrm{~m}$ and $\sim 200 \mathrm{gal}$ on the surface). Soil behavior in the upper layers can be described by a single, nonlinear stress-strain relation, and changes in the soil behavior are due to changes in the working areas of this curve, which depend on the intensity of the imposed seismic motion. Since soil conditions are similar at the three sites, the conclusion 
was made that the more complex soil behavior at PI and SGK was due to the more intense input motion at these sites (Pavlenko and Irikura, 2002a).

The 1995 Kobe earthquake was accompanied by several aftershocks just after the mainshock. In the present work, the described method is applied to estimate stress-strain relations during weaker motion, that is, in the aftershocks occurring within $5 \mathrm{~min}$ after the mainshock. We used the obtained stress-strain relations for aftershocks to estimate shear moduli at different depths at PI, SGK, and TKS sites. Temporal changes in shear moduli during the mainshock and subsequent aftershocks were traced, and estimates of a decrease in shear modulus are presented for PI, SGK, and TKS sites.

It should be mentioned that aftershocks were superimposed on the background of basin-induced surface waves, which occurred after the mainshock. Basin-induced waves recorded at PI and SGK sites after the mainshock can be treated as dynamic loading, and therefore, shear-modulus estimates for aftershocks were obtained in a dynamic regime.

\section{Data and Methods}

Records of the mainshock and the subsequent aftershocks recorded at sites PI, SGK, and TKS were studied. All of the sites are located around Osaka Bay and are close to the epicenter of the 1995 Kobe earthquake. The distances from PI, SGK, and TKS recording sites to the fault plane are $2 \mathrm{~km}, 6 \mathrm{~km}$, and $16 \mathrm{~km}$, respectively. Figure 1 shows the soil stratigraphy and the arrangement of recording devices at these sites. $P$-wave velocity indicates the groundwater level at $\sim 13 \mathrm{~m}$ at PI and 3-5 $\mathrm{m}$ at SGK and TKS sites.

The method of estimation of nonlinear stress-strain relations in layers from the surface down to the location of the deepest device has been described by Pavlenko and Irikura (2002a). To determine the stress-strain relations in different layers during strong ground motion, the medium from the surface down to the location of the deepest device was divided into groups of layers, for which various types of stress-strain relations were assumed according to the profiling data (Fig. 1). Three main types of stress-strain curves were considered: (1) curves similar to those obtained in laboratory experiments by Hardin and Drnevich (1972) to describe the behavior of dense soils at depth (18-27 $\mathrm{m}$ and 33$83 \mathrm{~m}$ at PI; below $11 \mathrm{~m}$ at SGK; and below $14 \mathrm{~m}$ at TKS); (2) curves of the "soft" type (Zvolinsky, 1982), similar to type 1 but with a much steeper slope, which are characteristic of liquefied soils (upper $0-13 \mathrm{~m}$ above the level of underground water at PI); (3) curves of the "hard" type, declining to the stress axis at large strains which are characteristic of water-saturated, sandy soils (Zvolinsky, 1982) (13-18 $\mathrm{m}$ and 27-33 $\mathrm{m}$ at PI; upper 0-11 $\mathrm{m}$ at SGK; upper $0-14 \mathrm{~m}$ at TKS). Thus, the choice of curves was physically justified. To account for temporal changes in the soil behavior, records were divided into intervals of $1.5-\mathrm{sec}$ duration.
Within each interval, the stress-strain relations were assumed to be stationary and to vary for different intervals. Calculations were performed successively, interval by interval, and groups of best-fit stress-strain curves were found for each interval for two horizontal components at PI, SGK, and TKS sites. The calculation algorithm based on the lumped-mass method (Joyner and Chen, 1975) was used.

In this work, the method was applied to aftershocks of the 1995 Kobe earthquake that occurred within 5 min after the mainshock, that is, to weak-motion records. Weak signals were found more difficult to analyze than strong ones, because in weak motion, the working areas of the stressstrain curves are located close to zero. As a result, many curves look similar, and the difference between records simulated with different curves is very small. Therefore, we used larger data lengths than in strong motion (10-40 sec instead of $1.5 \mathrm{sec}$ ), and we obtained the best-fit stress-strain curves averaged over these time intervals. However, parameters of the neighboring curves were close to each other, and inaccuracies in their estimation related to inadequate choice of curves were smaller than in the case of the mainshock.

Profiling data used for nonlinear simulation at site PI were taken from Aguirre and Irikura (1997). Data on shearwave velocity, shear-modulus degradation, and maximum shear strain at all depths at SGK and TKS sites were taken from Soeda et al. (1999) and were applied to calculate the shear stress in failure, $\tau_{\max }$, and the low-strain shear modulus, $G_{\max }$, in different layers, according to Seed et al. (1984) and Sun et al. (1988).

The obtained stress-strain relations in the mainshock and aftershocks were used to estimate shear moduli at different depths. We calculated $G_{\text {sec }}$, which approximates average values of $G_{\tan }$ over the entire stress-strain loops (Kramer, 1996). As explained previously, one stress-strain curve was used to describe the behavior of soils within a certain group of layers at a given time interval. However, the working areas of stress-strain curves differ from layer to layer within a group (as shown in Figs. 3b, 4b, and 5b), and estimates of $G_{\mathrm{sec}}$ vary within each group from layer to layer. Weighted-mean values of $G_{\text {sec }}$ were determined, which characterize average values of the shear modulus within a given group of layers at a given time interval.

Figure 2 shows accelerograms of the mainshock together with the first aftershocks at PI, SGK, and TKS sites. Long-period waves recorded in horizontal components at PI and SGK sites may be standing waves due to $S$-wave reverberation in the basin sediments, probably including basininduced surface waves (Hatayama et al., 1995; Pitarka et al., 1998). Both sites PI and SGK belong to the Osaka basin, and the corresponding depths to the basement are 1,0001,200 m and 1,200-1,400 m, respectively (Hatayama et al., 1995). Amplitudes of these waves achieved $\sim 5 \mathrm{~cm} / \mathrm{sec}^{2}$ at site SGK and $\sim 3 \mathrm{~cm} / \mathrm{sec}^{2}$ at PI, and the period was about 4 $6 \mathrm{sec}$. Basin-induced waves were not recorded at site TKS because of its location outside the limits of the Osaka basin, on the other side of the fault plane (Hatayama et al., 1995). 


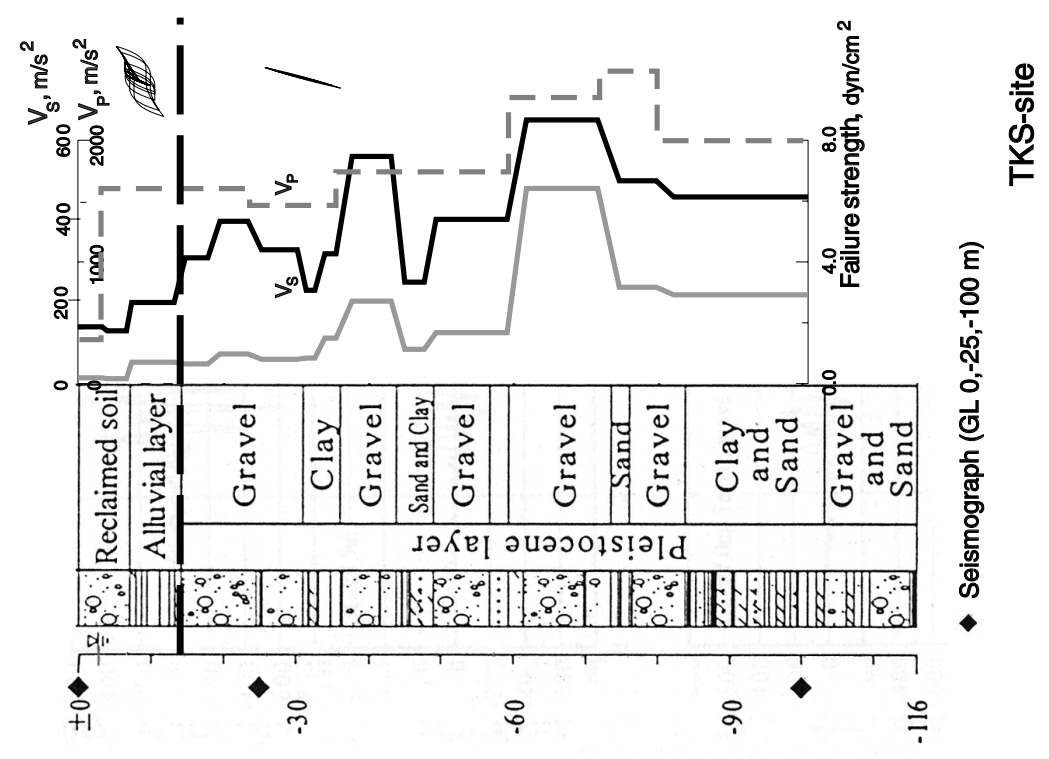

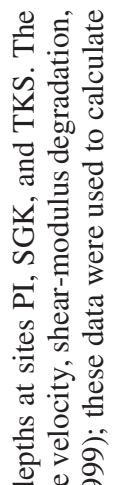

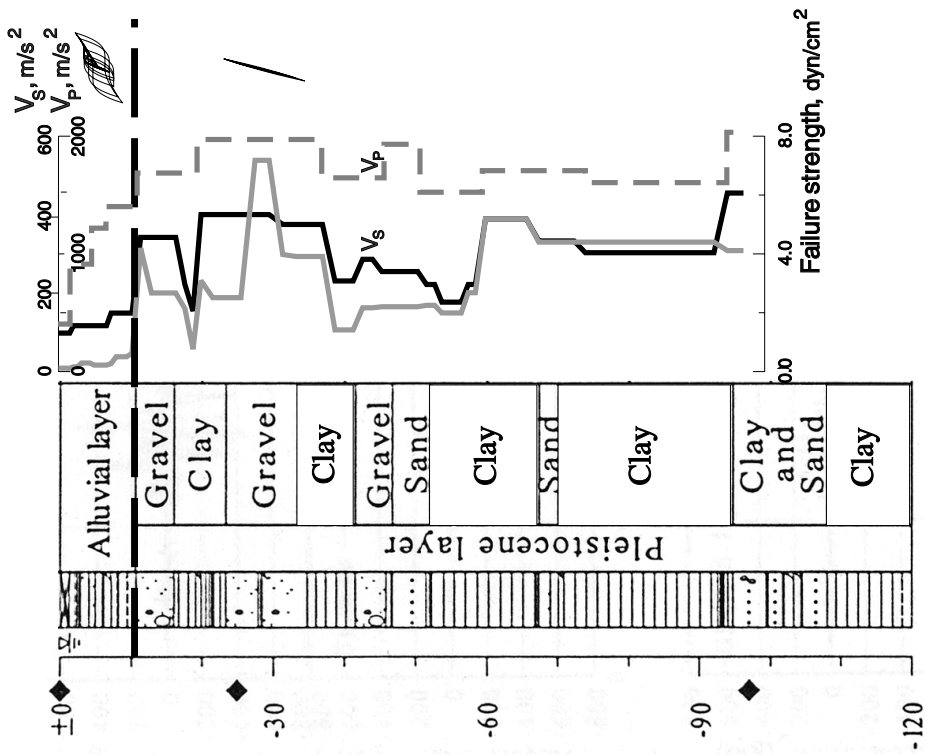

高

.

牙芆

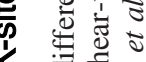

可

稌

ค็

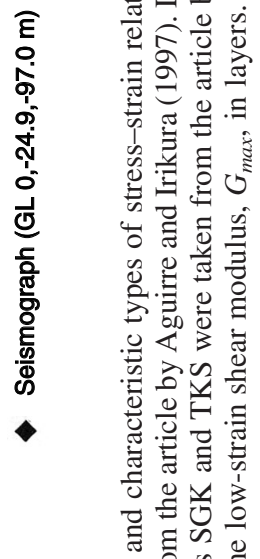

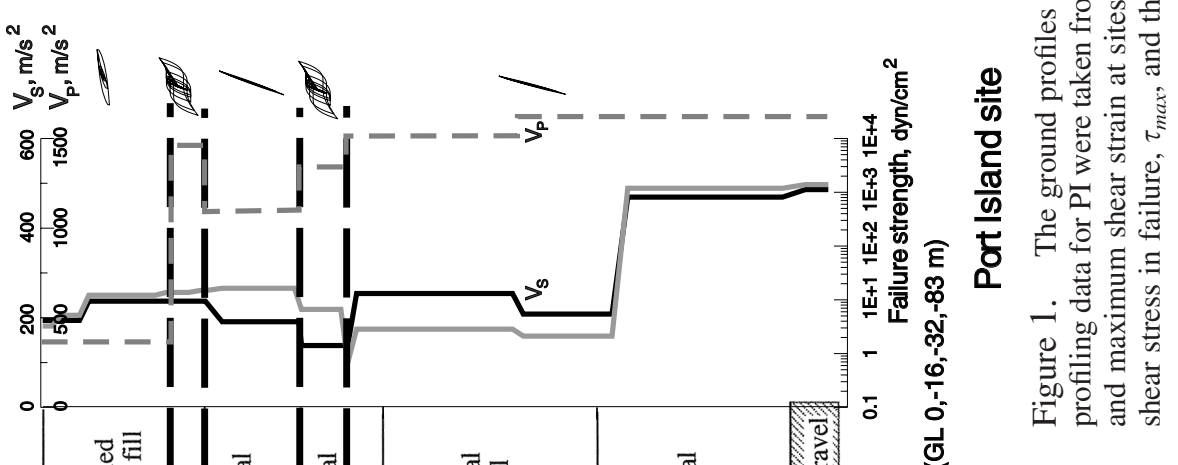



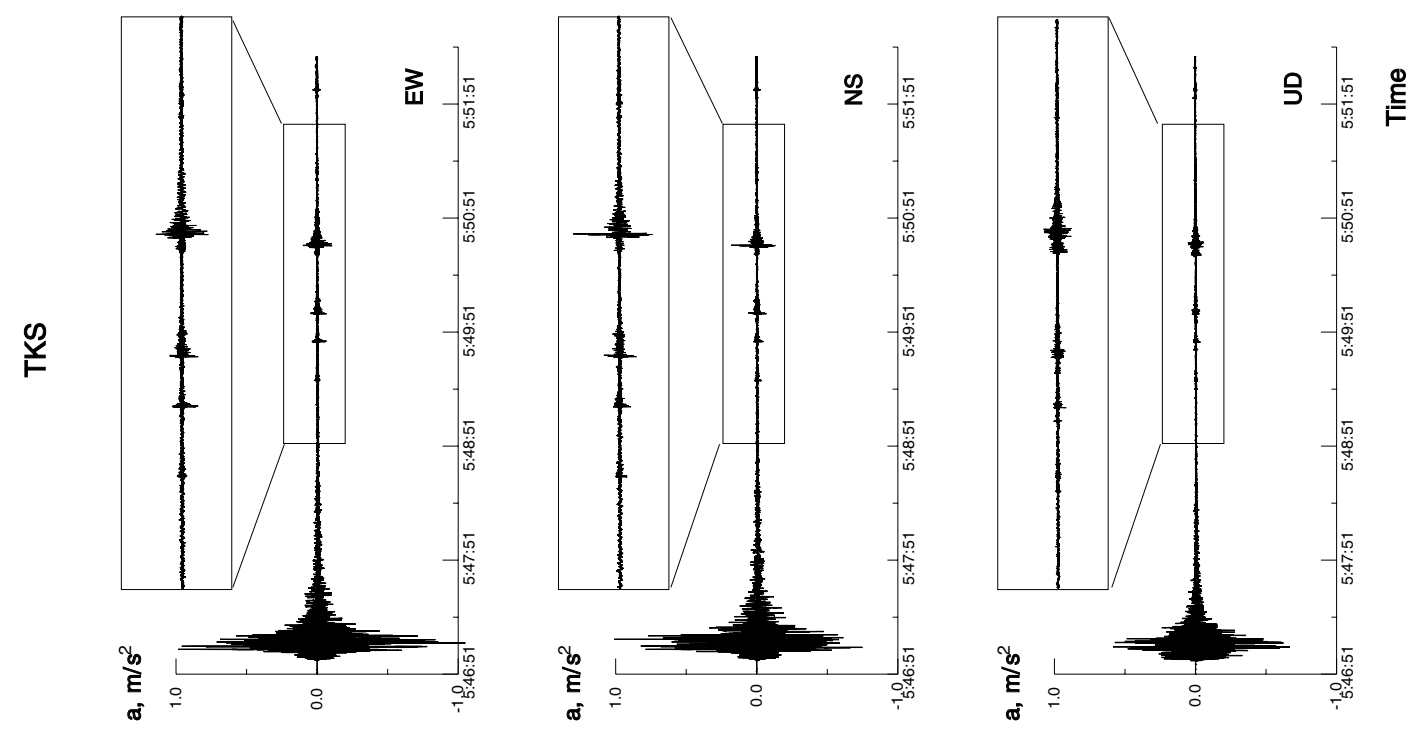

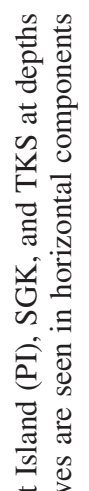
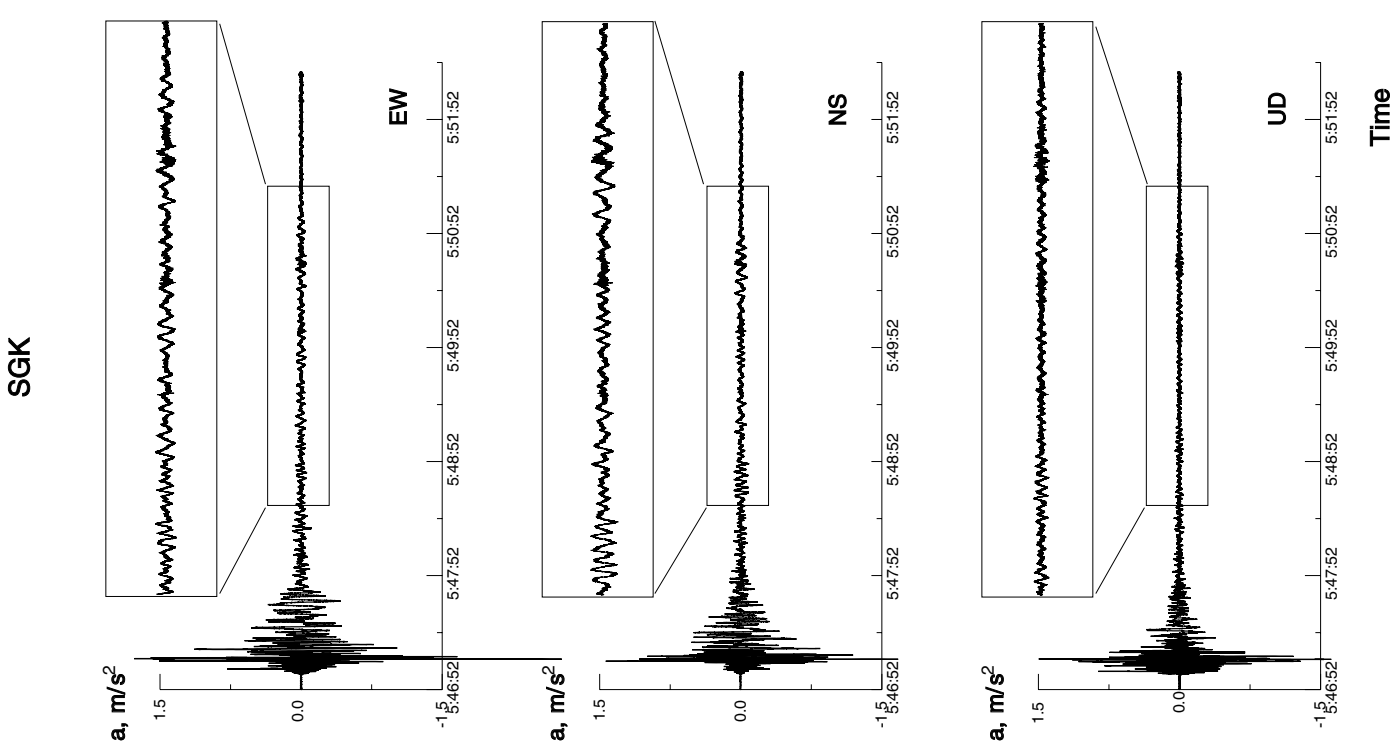

突

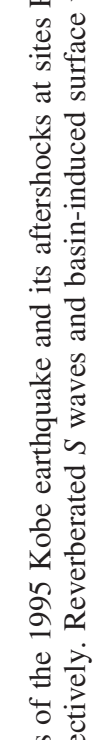

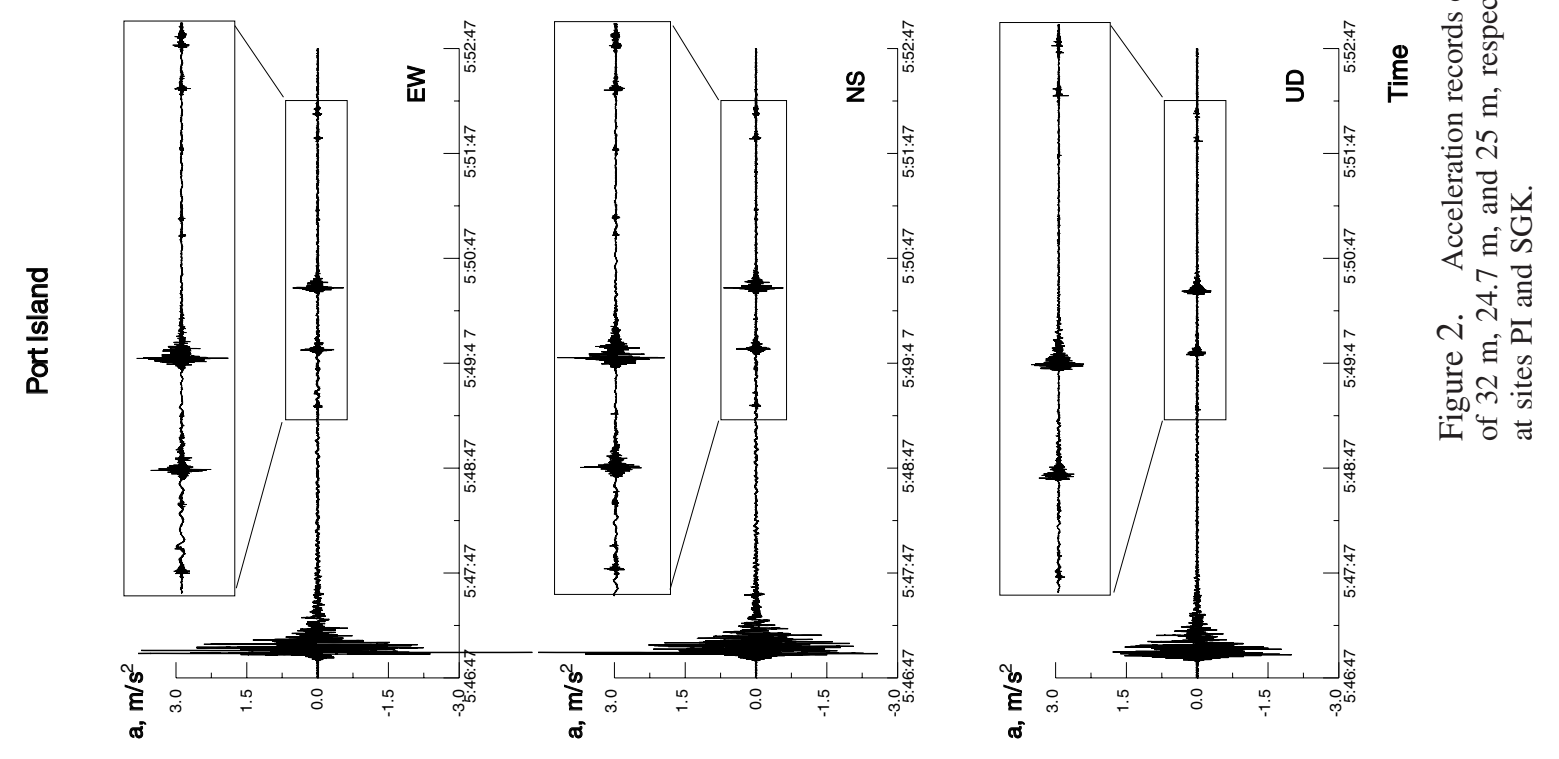




\section{Results and Discussion}

At PI, the strongest horizontal accelerations were measured during the mainshock $(\sim 500$ gal for E-W and $\sim 600$ gal for $\mathrm{N}-\mathrm{S}$ at $83 \mathrm{~m}$ ), and liquefaction occurred in the upper layers $(0-13 \mathrm{~m})$. First aftershocks were recorded immediately after the mainshock, when the surface soils were still in a liquefied state. Figure 3 a shows the observed and simulated records of the first five aftershocks at PI. Figure $3 b$ represents the corresponding stress-strain relations to depths of $43 \mathrm{~m}$, which characterize soil behavior during the mainshock and aftershocks. In the case of the mainshock, the stress-strain relations were obtained for 10 successive 1.5sec time intervals, whereas for the aftershocks, each group of curves corresponds to one aftershock. The whole set of observed and simulated records of the mainshock at the three sites is presented in Pavlenko and Irikura (2002a).

Progressive liquefaction within the upper 0-13 m during the mainshock can be traced by the evolution of stress-strain relations: their slope decreases with increasing time, indicating a substantial reduction in shear modulus to approximately near-zero values (Fig. 3b). Stress-strain relations obtained for aftershocks at PI also show large slopes for the upper $0-13 \mathrm{~m}$; however, these slopes are slightly steeper than those obtained for final parts of the mainshock. This can indicate the beginning of shear-modulus recovery a few minutes after the mainshock.

At sites SGK and TKS, the imposed accelerations were not as high as at PI ( $\sim 300$ gal and $\sim 100$ gal, respectively). Figure $4 \mathrm{a}$ and $4 \mathrm{~b}$ shows the observed and simulated aftershocks and the corresponding stress-strain relations, respectively, for the mainshock and aftershocks at site SGK. Changes in soil behavior occurred in the upper 0-11 $\mathrm{m}$ and can be traced by changes in the shapes of the stress-strain curves. Stress-strain relations characterizing the soil behavior in the aftershocks show a complete recovery of the shear modulus for the upper layers. At site TKS, the soil behavior of the upper 0-14 $\mathrm{m}$ during the mainshock and aftershocks can be described by a single stress-strain relation. Changes in the shear modulus are due to changes in the working areas of this curve, depending on the intensity of the imposed motion. The observed and simulated accelerograms of aftershocks at site TKS are presented in Figure 5a, and the corresponding stress-strain curves for the mainshock and the aftershocks are shown in Figure 5b.

The difference between aftershocks recorded in liquefied (PI) and nonliquefied (SGK and TKS sites) soils is clearly seen in Figures 3a, 4a, and 5a. At sites SGK and TKS, acceleration amplitudes on the surface were noticeably higher than at the PI site. A "natural" amplification of seismic waves in the upper layers was observed at SGK and TKS sites (Figs. 4a and 5a), whereas at PI, where soils were liquefied, the acceleration amplitudes were very small on the surface for all aftershocks except the last one, which showed higher amplitudes. This confirms that 5 min after the ter- mination of strong motion, recovery of shear moduli in liquefied layers was already noticeable.

Figure 6a-6e shows summary plots of shear moduli in layers 0-13 m (a), 13-18 m (b), and 27-32.5 m (c) at PI; 0$11 \mathrm{~m}$ at SGK (d); and 0-14 $\mathrm{m}$ at TKS (e) as estimated for two horizontal components during the mainshock and aftershocks. These estimates are based on the corresponding stress-strain relations shown in Figures $3 b, 4 b$, and 5b. Below the shear-moduli curves, the corresponding observed and simulated acceleration-time histories of the mainshock are presented. Simulated records correspond to shear-moduli evolution. A good agreement between the observed and simulated records testifies to the validity of the obtained shearmoduli estimates.

To evaluate the accuracy of the obtained shear-moduli values, we analyzed two main sources of possible errors: (1) errors introduced by inexact determination of stress-strain relations in the layers and (2) scattering of shear-modulus estimates within groups of layers. Errors introduced by inexact determination of stress-strain relations in layers can be roughly evaluated by deviations of the simulated records from the observed ones. For the mainshock, these meansquare deviations, normalized by the intensities of the observed records, are $\sim 0.3-0.4$ for PI for frequencies up to $12 \mathrm{~Hz}$ and for site SGK, for frequencies up to $20 \mathrm{~Hz}$, and slightly higher, $\sim 0.5-0.6$ for TKS site, for frequencies up to $20 \mathrm{~Hz}$. For aftershocks at PI, SGK, and TKS, these values are higher: $\sim 0.8-1.3, \sim 0.6-0.8$, and $\sim 0.7-1.2$, respectively, for frequencies up to $20 \mathrm{~Hz}$. These values and accelerationtime histories show a rather good agreement between the observed and simulated motions. Thus, although the errors introduced by inexact determination of the stress-strain relations in layers can reach tens of percent, accounting for the large numbers of points and the conformity of estimates obtained for E-W and N-S components, we conclude that the main trends of shear-moduli changes were found correctly. Scattering (i.e., variations) of shear-modulus estimates within groups of layers is due to the fact that although the stress-strain relation is the same for all of the layers within the group, the working intervals are different for different layers, depending on elastic parameters of the layers. Therefore, shear-modulus estimates vary within each group, and we used the mean values and calculated confidence limits, which are shown in Figure 6a. They are not shown in other figures because of their smallness.

\section{PI Site}

In the upper 0-13 $\mathrm{m}$ at PI, shear modulus decreased gradually during the mainshock (Fig 6a). The decrease was most noticeable in the first 3-5 sec of strong motion, when it achieved $\sim 80 \%-90 \%$ of the initial value. Shear modulus reached its minimum during the following 5-7 sec and showed a tendency to increase a few minutes after a decrease in the intensity of the strong motion. Scattering of shearmodulus estimates corresponding to aftershocks indicated that recovery of shear modulus proceeded nonuniformly, 
(a)

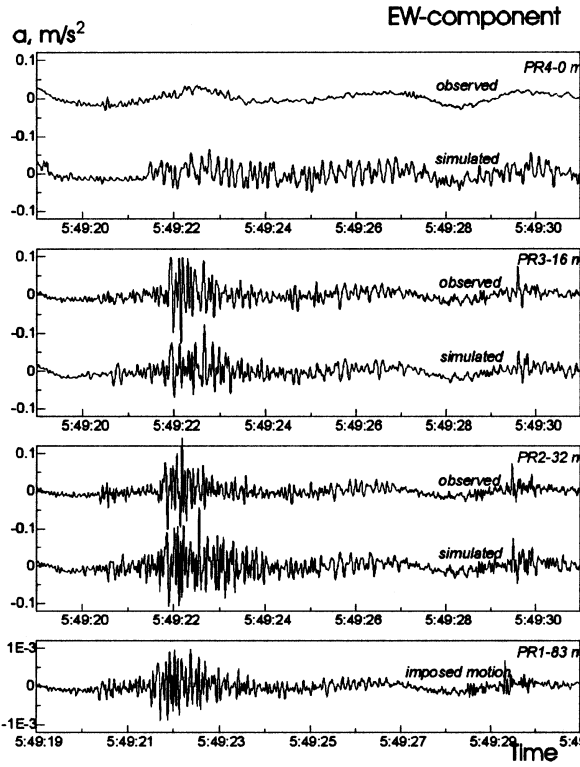

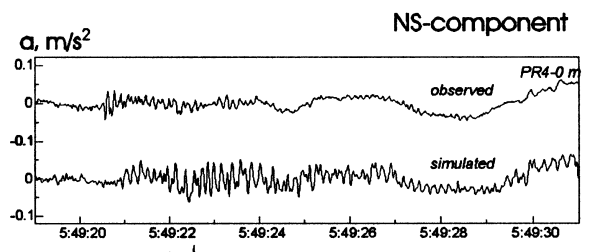
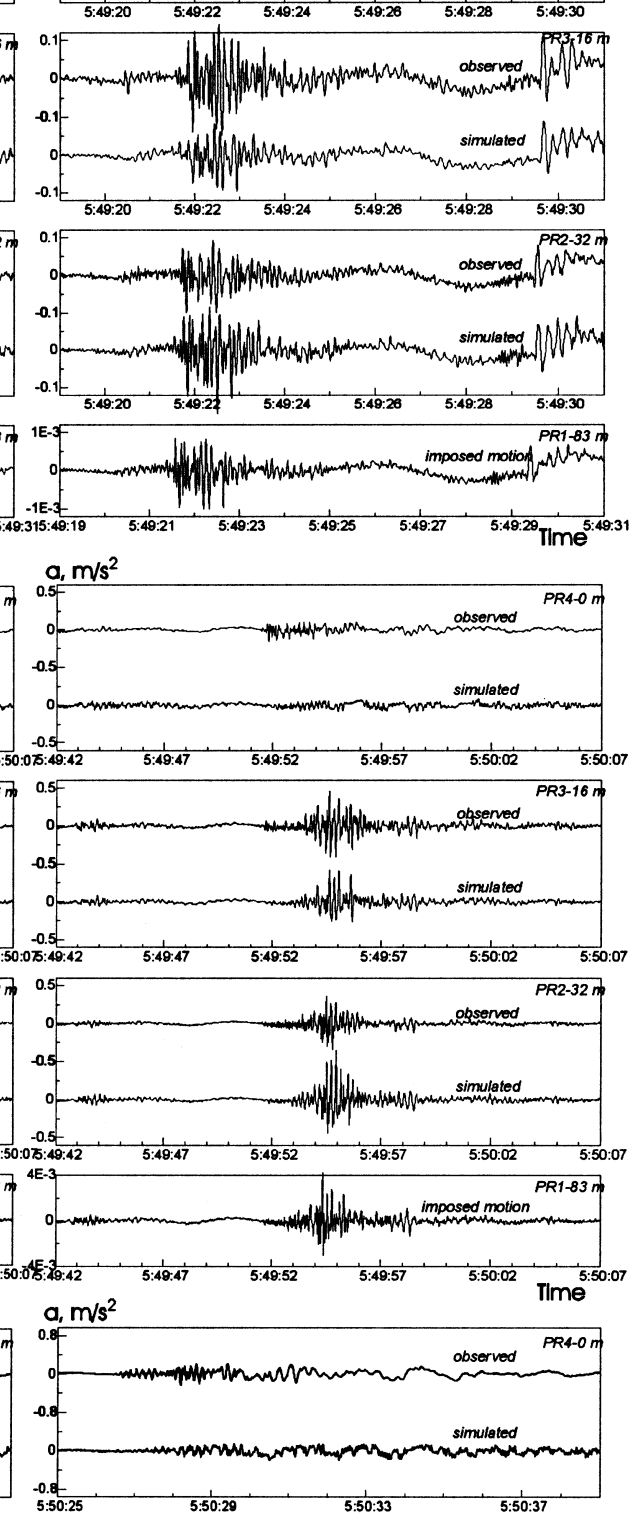

.
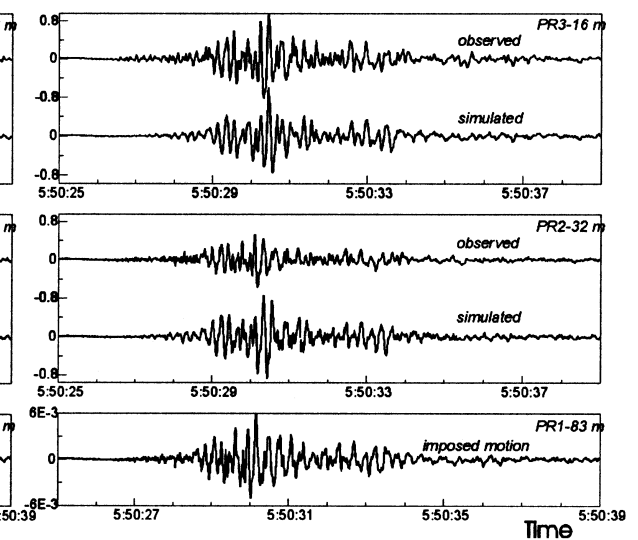

Figure 3. (Caption on next page.) 
(a)
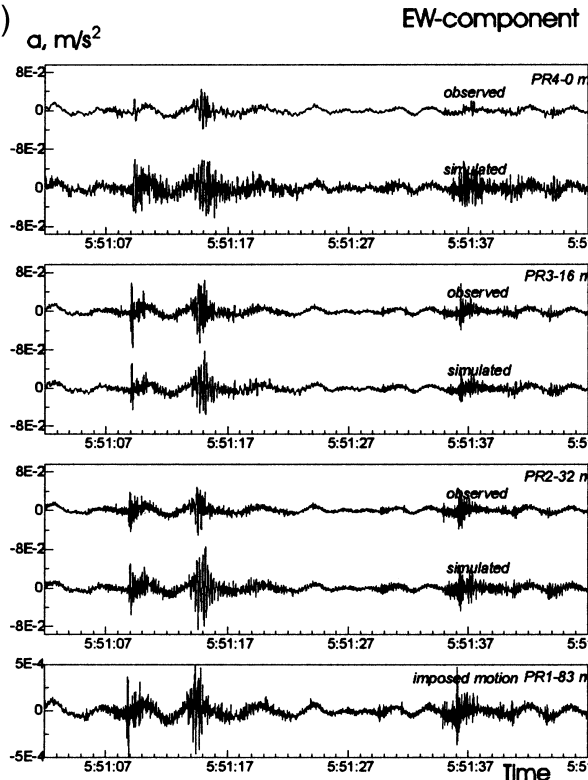

a, $\mathrm{m} / \mathrm{s}^{2}$
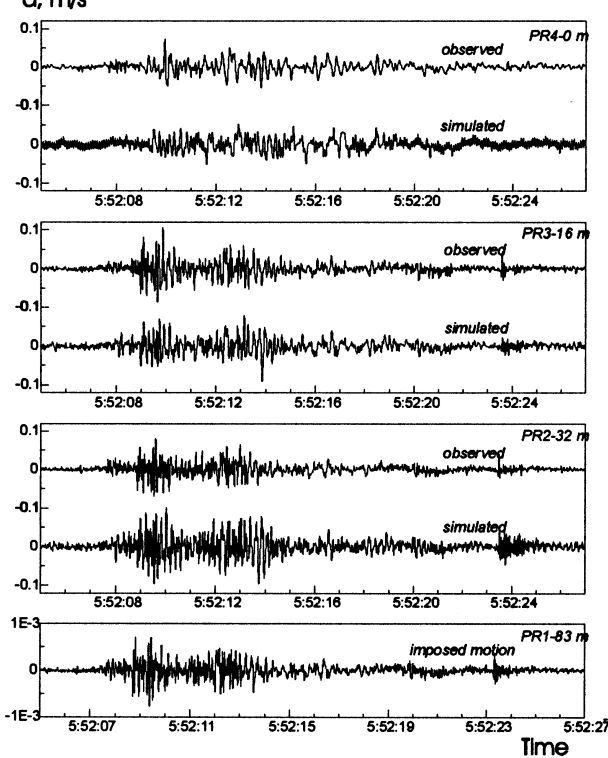

a. $m / s^{2}$
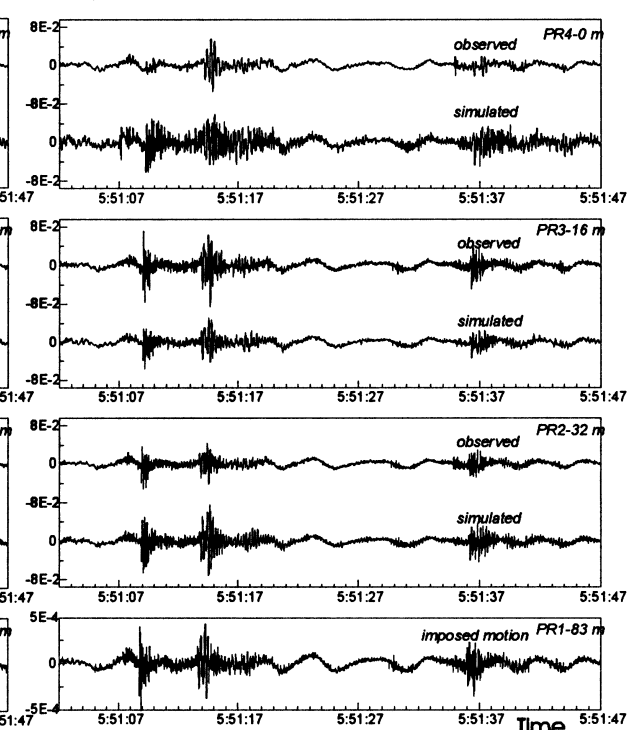

$a, m / s^{2}$
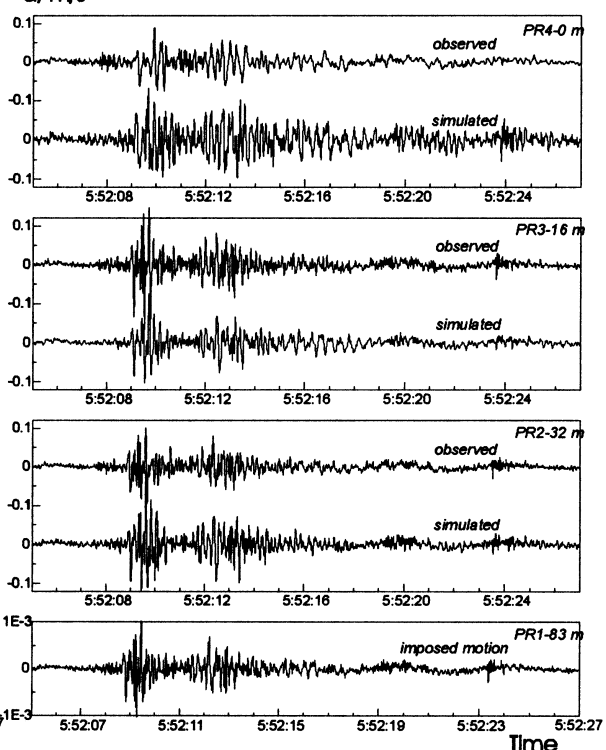

Figure 3. Acceleration-time histories of aftershocks in PI, observed and simulated (a), and the obtained stress-strain relations for the mainshock and aftershocks at PI (b). The stress-strain curves are scaled in relative units, which are the same for all time intervals at a given depth. Stress and strain are scaled in the manner described by Joyner and Chen (1975); stress was normalized by multiplying by $1 / \tau_{\max }$, and strain was normalized by multiplying by $G_{\max } / \tau_{\max }$.

(Continued on next page.)

which can be attributed to the movement of groundwater. The upper subsoil layer is a decomposed granite soil called "Masado," which is a sandy soil with much gravel, silt, and clay, and the contents of gravel and fines are $\sim 0 \%-65 \%$ and 5\%-35\%, respectively (Yasuda et al., 1996). According to many researchers, the presence in soil of even a small quantity of clay particles (1.5\%-2\% by Gumensky, 1965) imparts thixotropic properties to the soil (Boswell, 1949; Akkerman, 1958; Gumensky, 1965). Soils like Masado, which contain small quantities of fines, possess intermediate properties between noncohesive and cohesive (quasi-thixotropic) soils.
For such weakly cohesive soils, a quick decrease in rigidity even for rather low levels of dynamic loading is typical, which is due to their mixed composition. In such soils, the Coulomb friction is less than in a pure sand, and the coagulation lattice is weak and usually discontinuous. The decreased permeability hampers the dissipation of pore pressure and facilitates liquefaction. In such soils, gradual and slow hardening after termination of dynamic loading includes two processes, such as weak compression of the soil accompanied by the loss of water and thixotropic strengthening of the coagulation lattice. The compression proceeds 


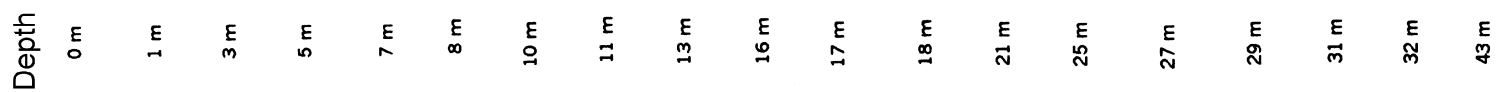

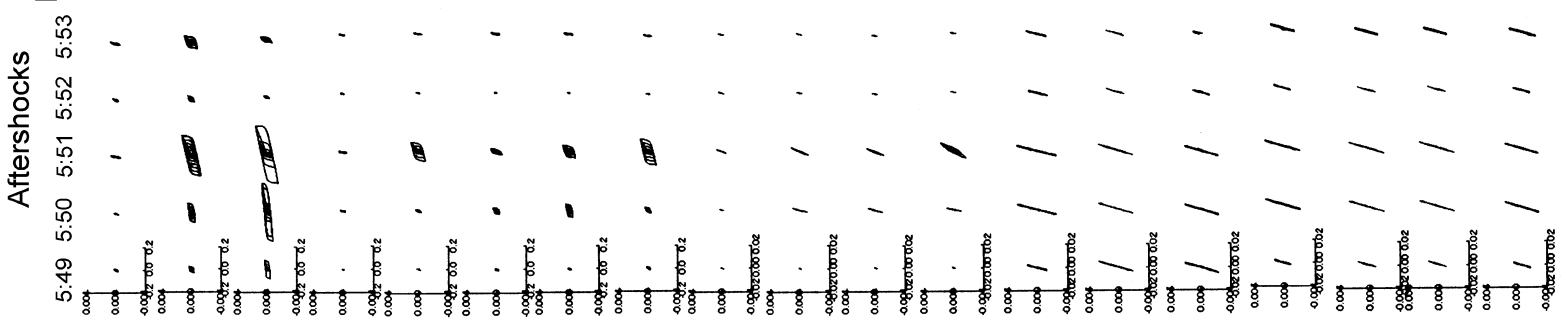

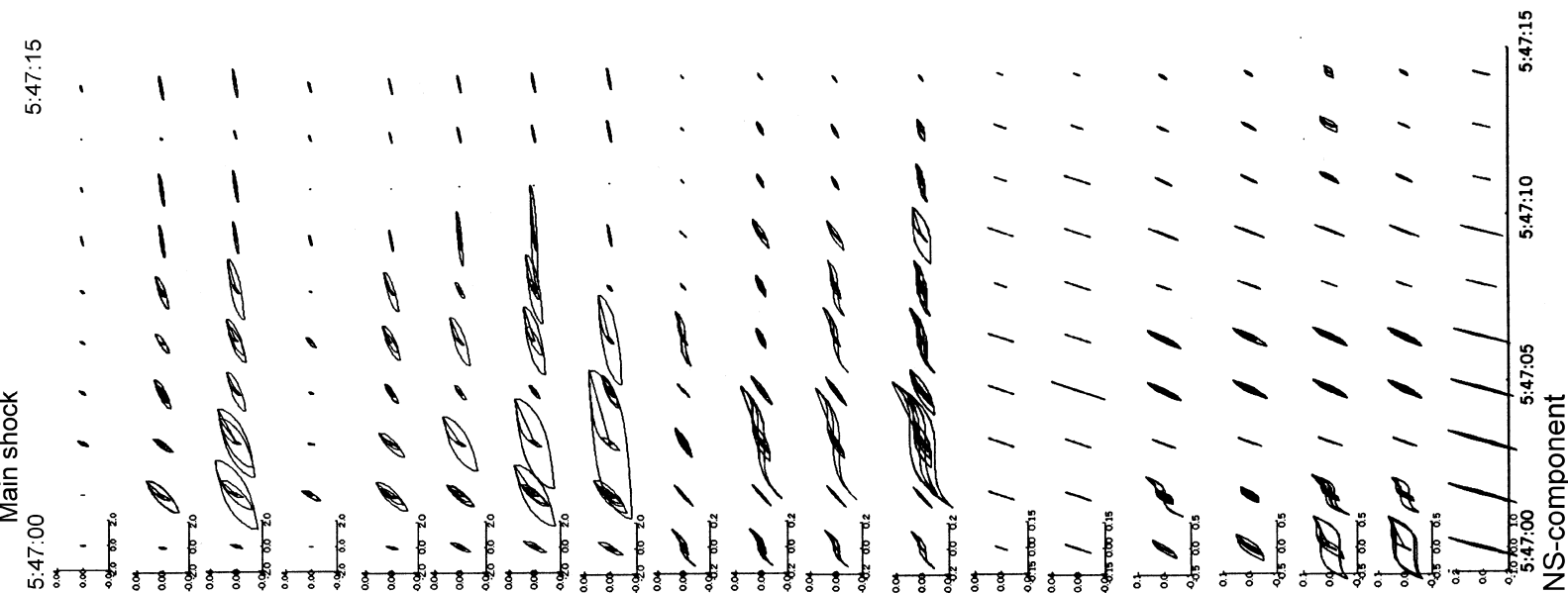

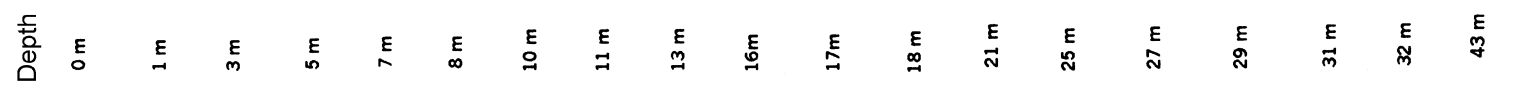
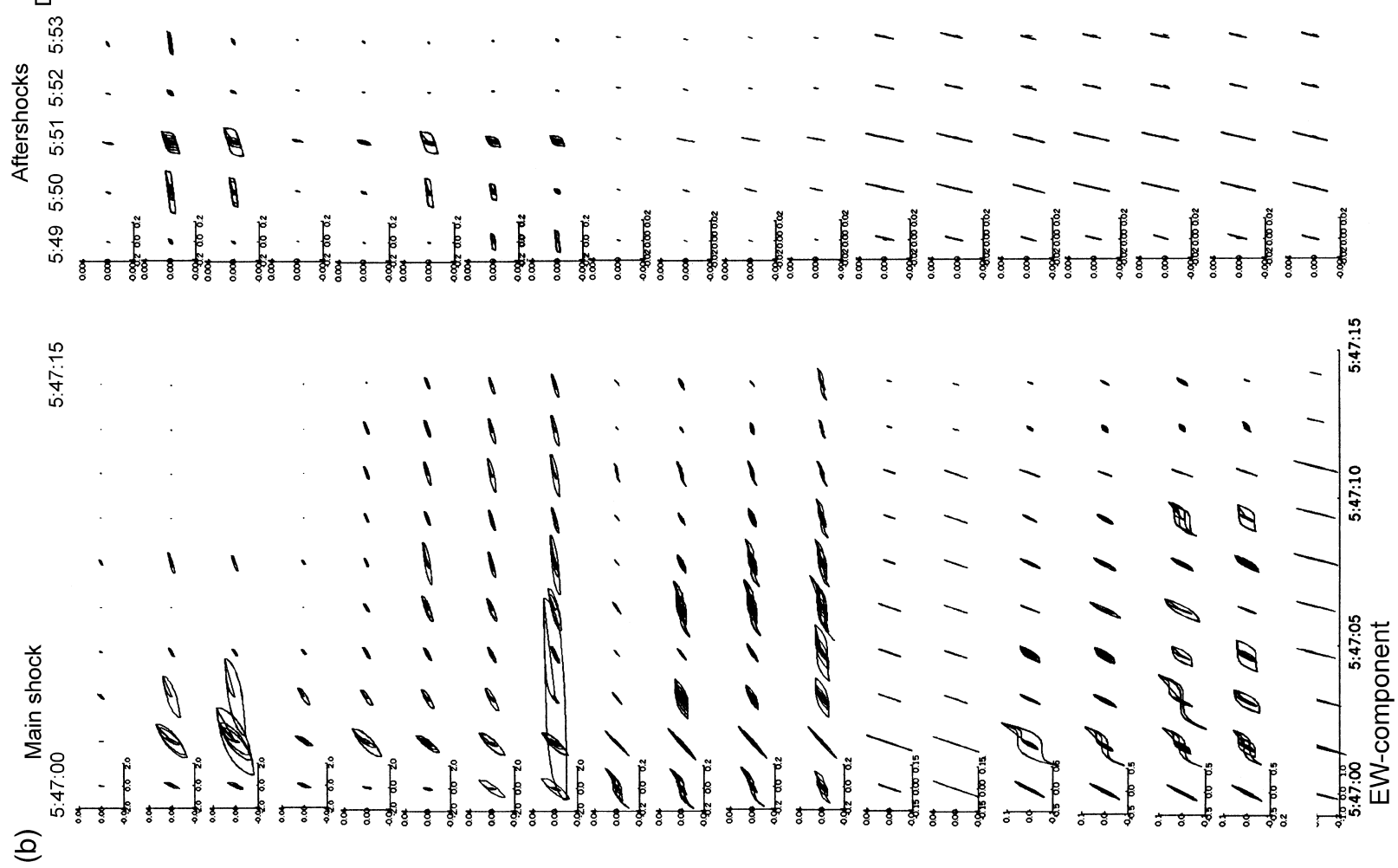
(a) $a, m / s^{2}$
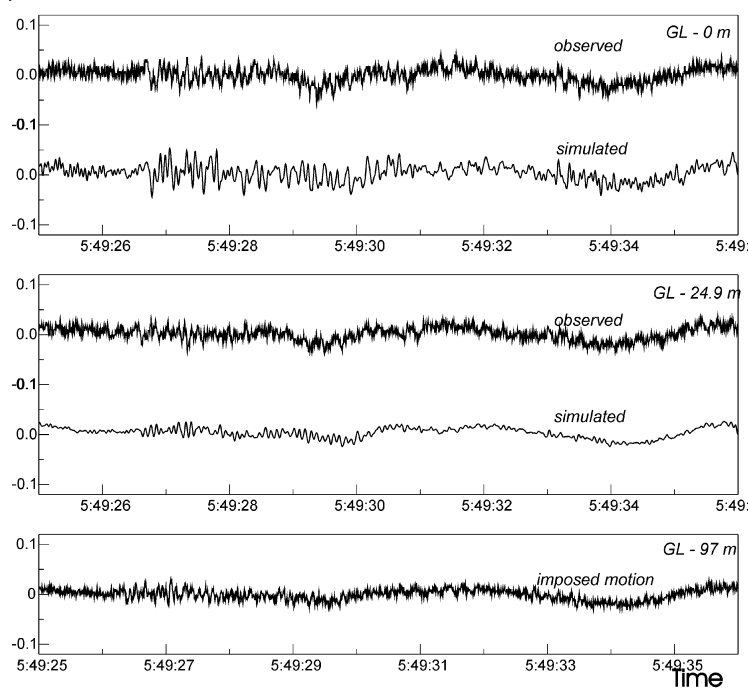

$\mathrm{a}, \mathrm{m} / \mathrm{s}^{2}$
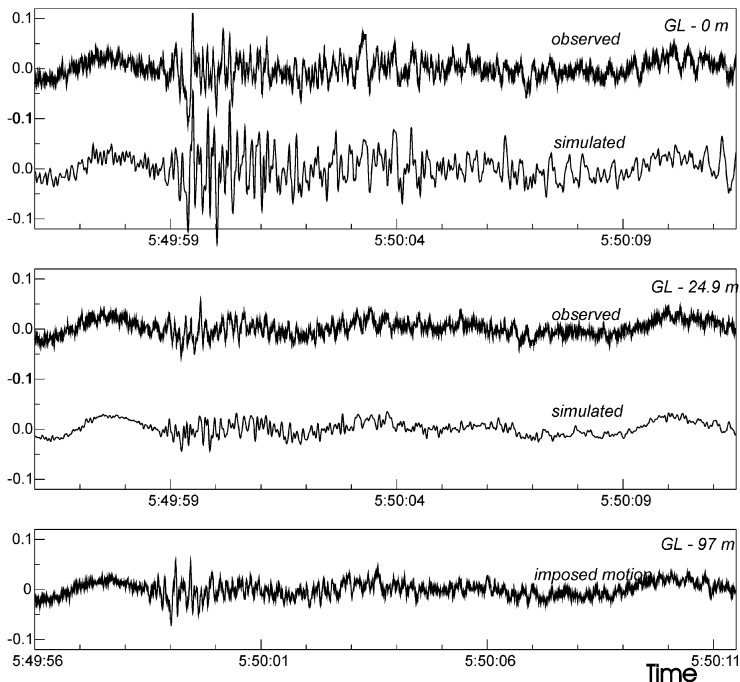

$\mathrm{a}, \mathrm{m} / \mathrm{s}^{2}$
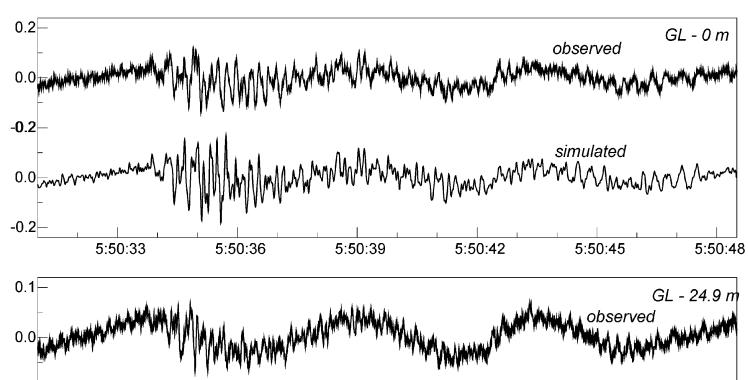

0.1
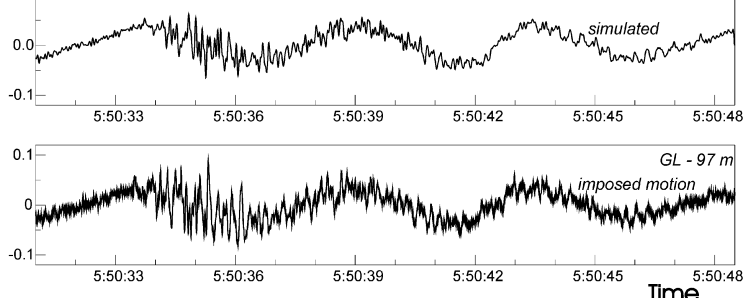

$\mathrm{a}, \mathrm{m} / \mathrm{s}^{2}$

NS-component
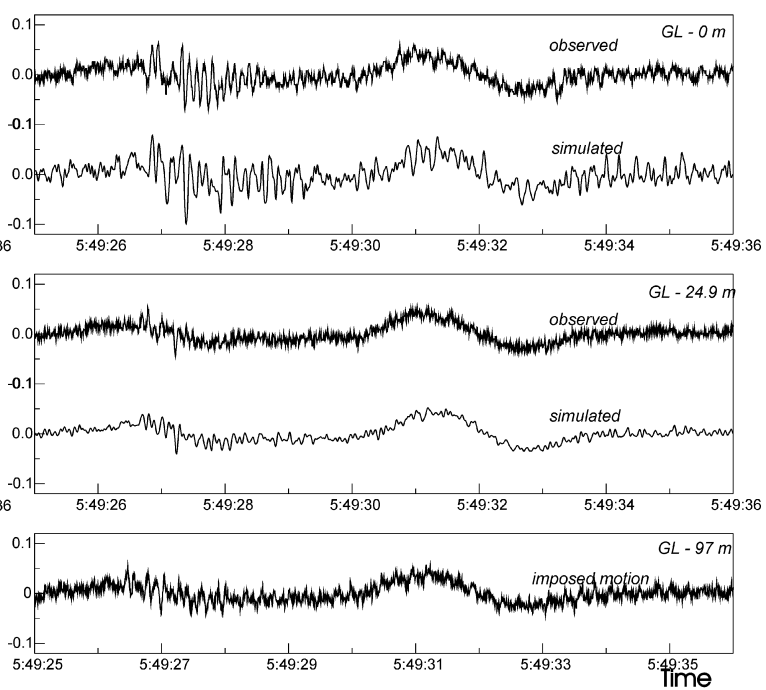

$\mathrm{a}, \mathrm{m} / \mathrm{s}^{2}$
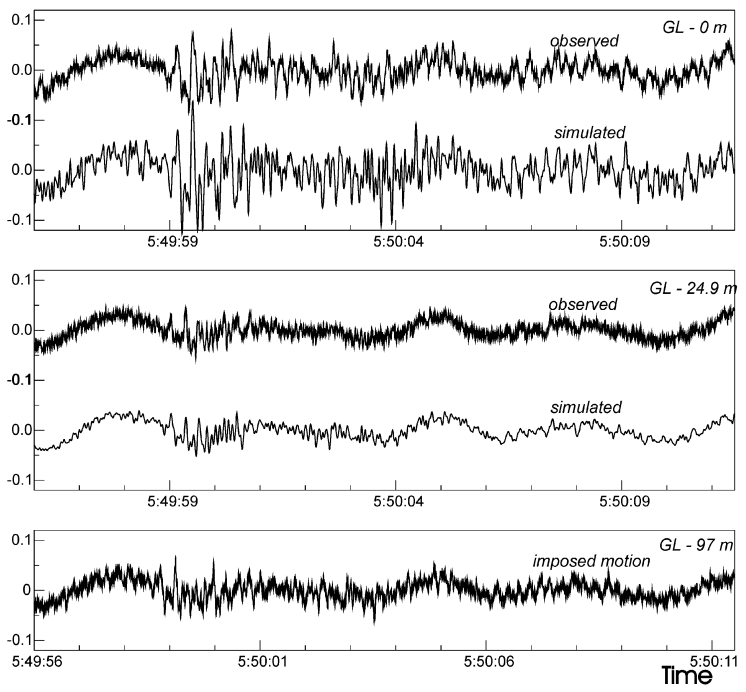

$\mathrm{a}, \mathrm{m} / \mathrm{s}^{2}$
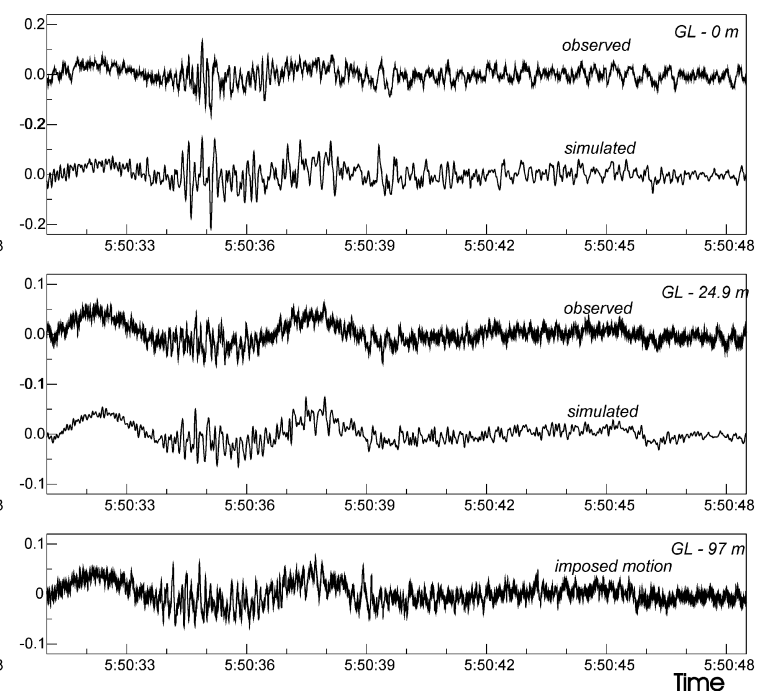

Figure 4. Acceleration-time histories of aftershocks at site SGK, observed and simulated (a), and the obtained stressstrain relations for the mainshock and aftershocks at SGK (b). The axes scales of the stress-strain curves are in relative units, which are the same for all time intervals at a given depth. Stress and strain are scaled as in Figure $3 b$. 

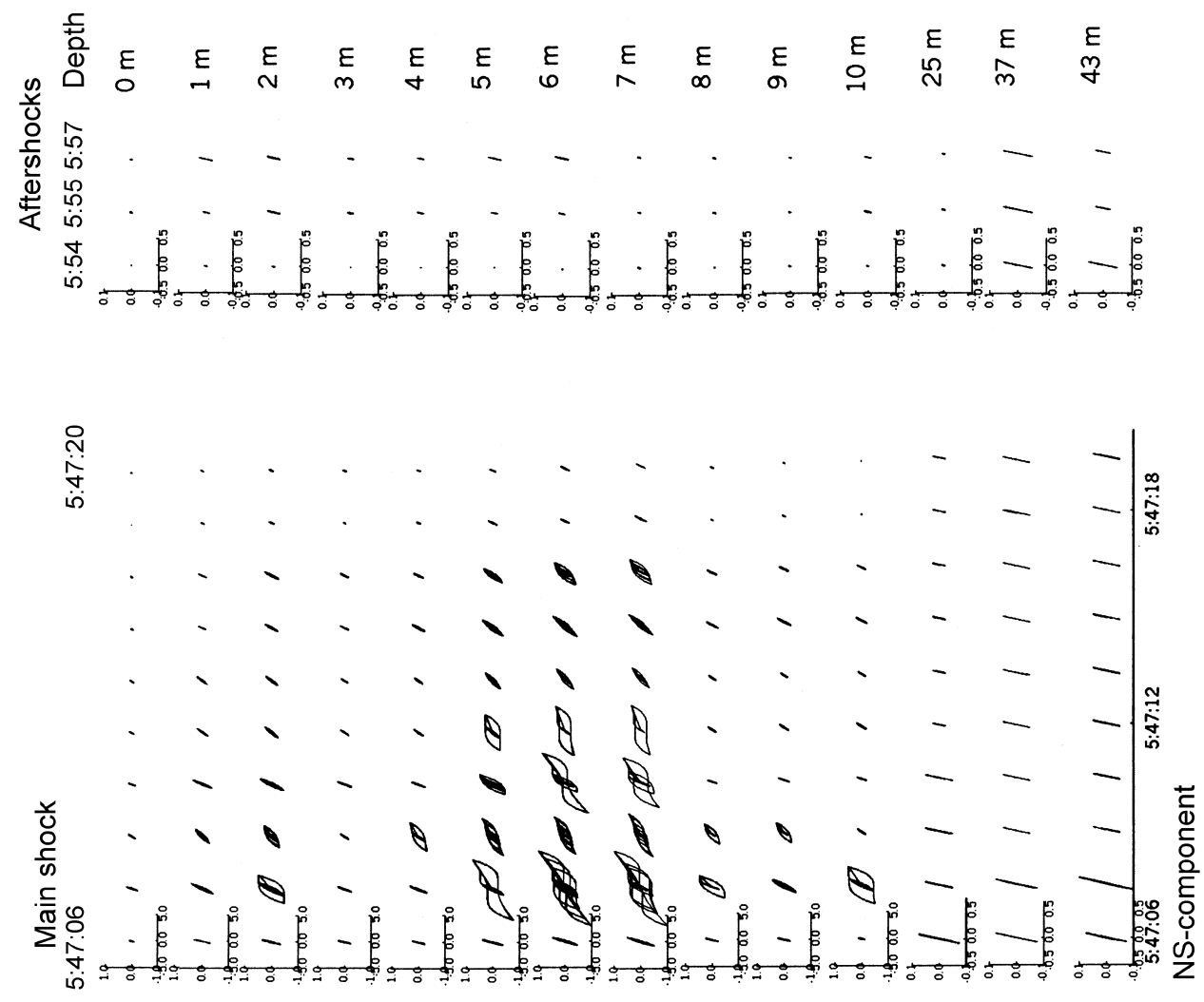

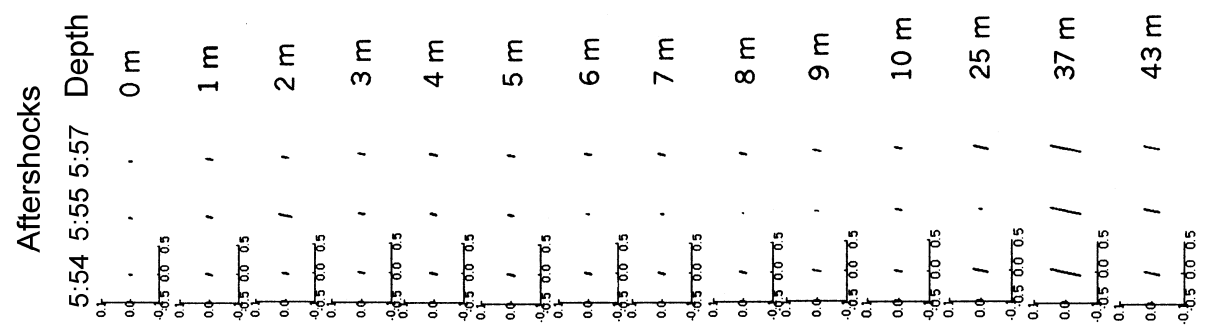

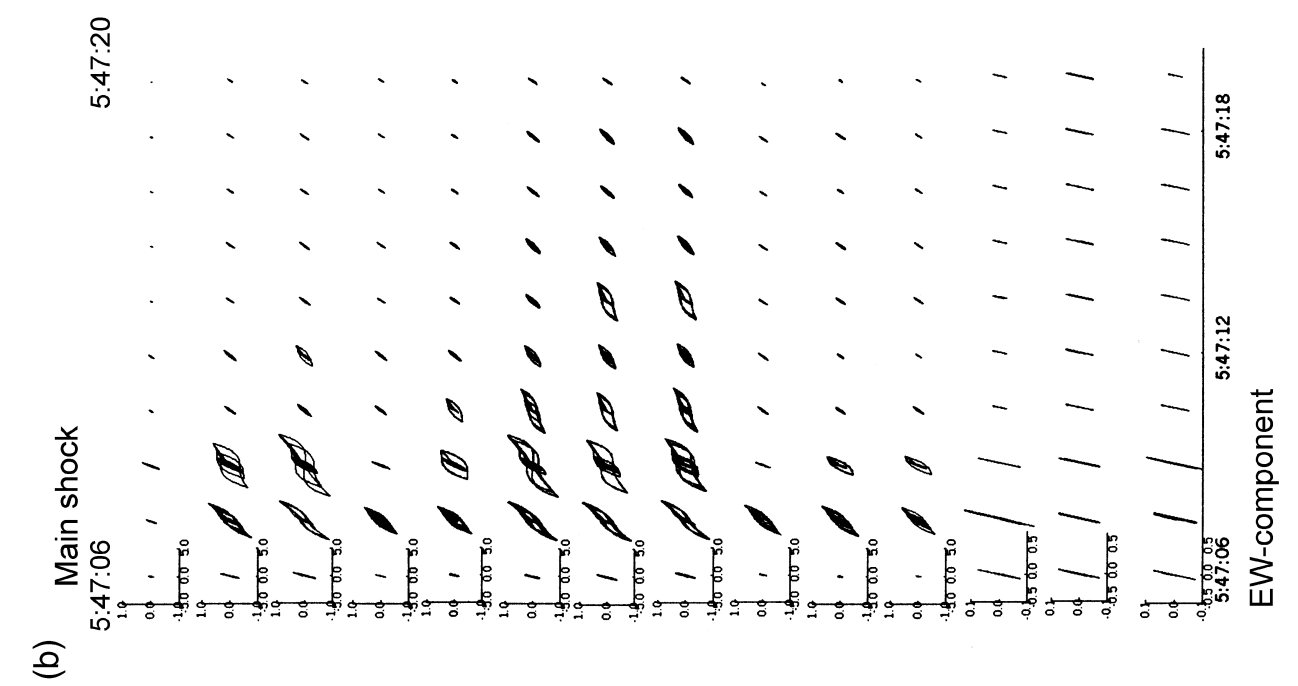


(a) $a, m / s^{2}$
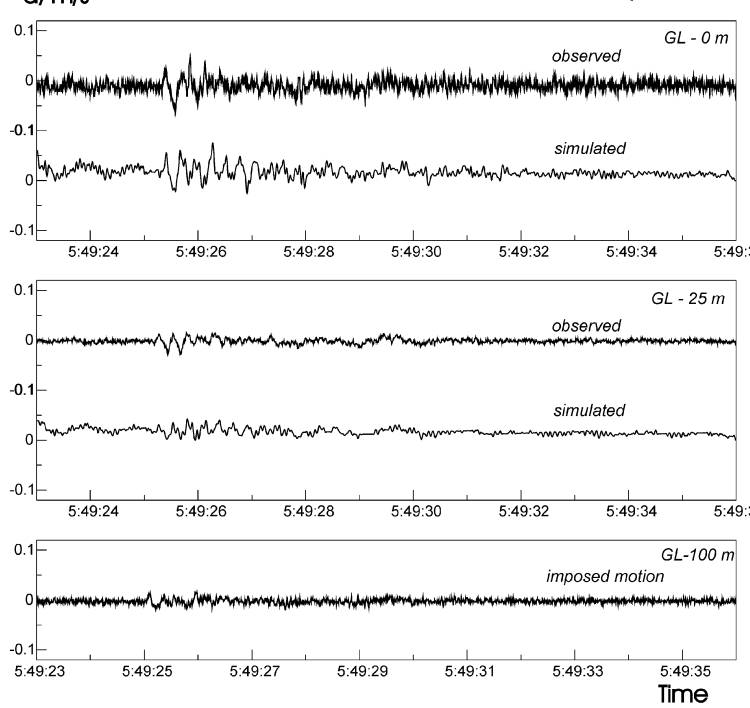

$\mathrm{a}, \mathrm{m} / \mathrm{s}^{2}$
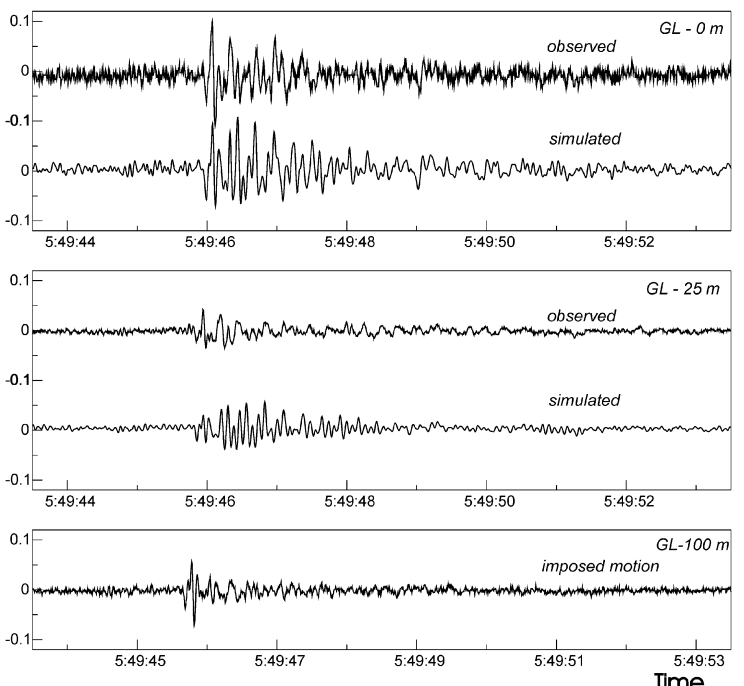

$\mathrm{a}, \mathrm{m} / \mathrm{s}^{2}$
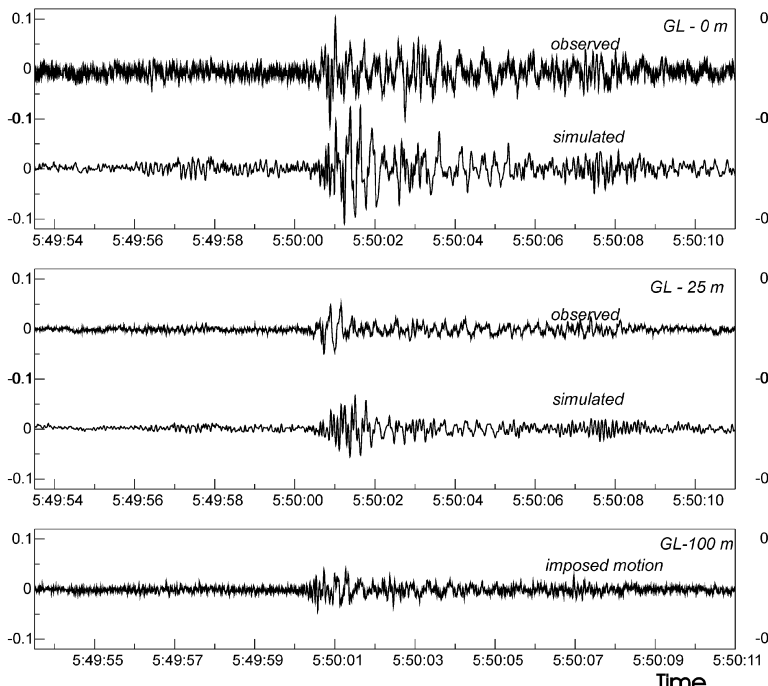

$\mathrm{a}, \mathrm{m} / \mathrm{s}^{2}$

NS-component
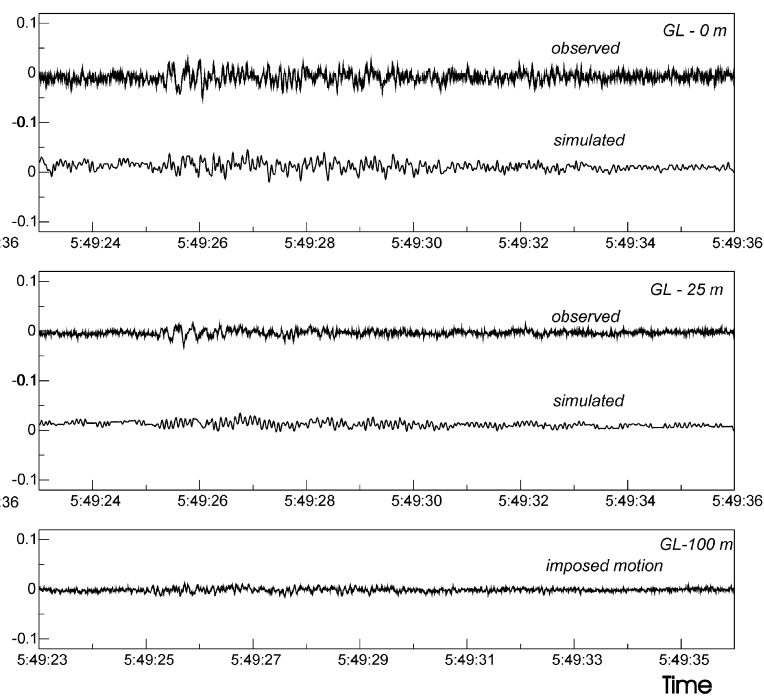

$\mathrm{a}, \mathrm{m} / \mathrm{s}^{2}$
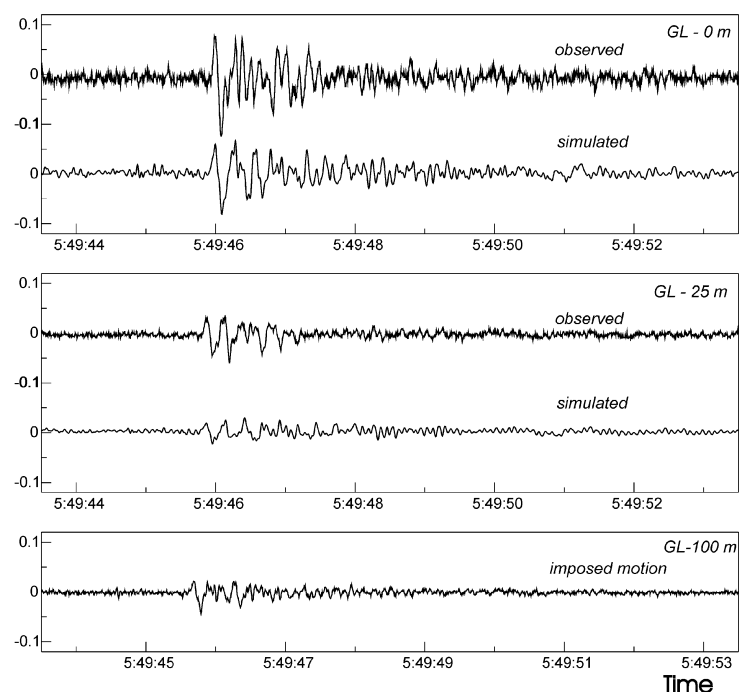

$\mathrm{a}, \mathrm{m} / \mathrm{s}^{2}$
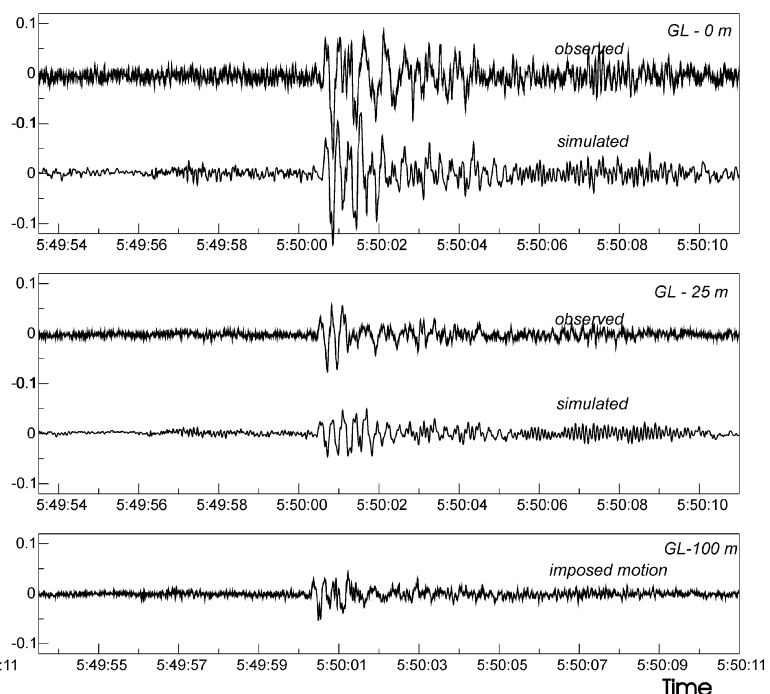

Figure 5. (Caption on next page.) 
(a)
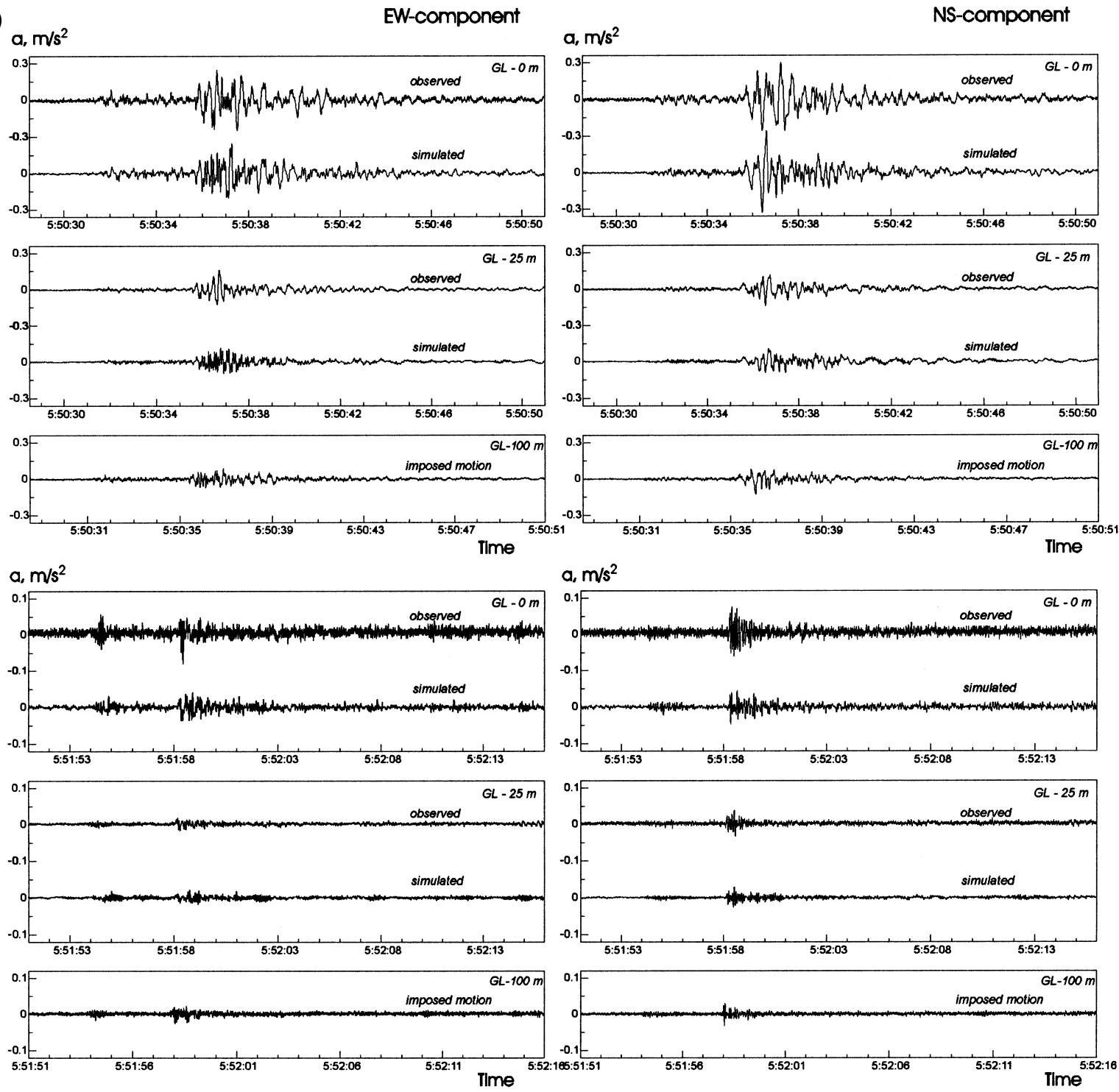

Figure 5. (Continued) Acceleration-time histories of aftershocks at site TKS, observed and simulated (a), and the obtained stress-strain relations for the mainshock and aftershocks at TKS (b). The axes scales of the stress-strain curves are in relative units, which are the same for all time intervals at a given depth. Stress and strain are scaled as in Figure $3 \mathrm{~b}$.

in accord with the dissipation of pore pressure, and its rate is determined by the filtering properties of a soil, whereas the thixotropic strengthening takes several hours (maximum, 1 day) and proceeds rather nonuniformly during the first few minutes owing to continued water movement (Voznesensky, 1999). This recovery mechanism consisting of the two processes, pore pressure dissipation and thixotropic strengthening, seems to be probable at PI, considering the soil composition, the nonuniformity of recovery during the first few minutes (Fig. 6a, 6b, 6d, 6e), and the total time for recovery, which was estimated by Aguirre and Irikura (1997). They showed by means of $S$-wave-velocity inversion and simulation of the $S$-wave propagation accounting for the soil non- linearity, that (1) the rigidity of the upper layers decreased sharply during the largest ground shaking before liquefaction happened; (2) the biggest change in the soil rigidity was observed several seconds after the occurrence of liquefaction and then it gradually recovered; (3) the most noticeable changes in shear moduli occurred in the layer from 5 to 16 $m$ depth; and (4) the aftereffects of liquefaction remained at least 3 hours after the mainshock but no more than 24 hours.

Figure $6 \mathrm{~b}$ shows the changes in shear modulus at depths of 13-18 $\mathrm{m}$ and the corresponding observed and simulated accelerograms at $16 \mathrm{~m}$. Changes in the shear moduli in this layer during the first few seconds of strong motion were as large as in the surface layer. The composition of soils at 13- 

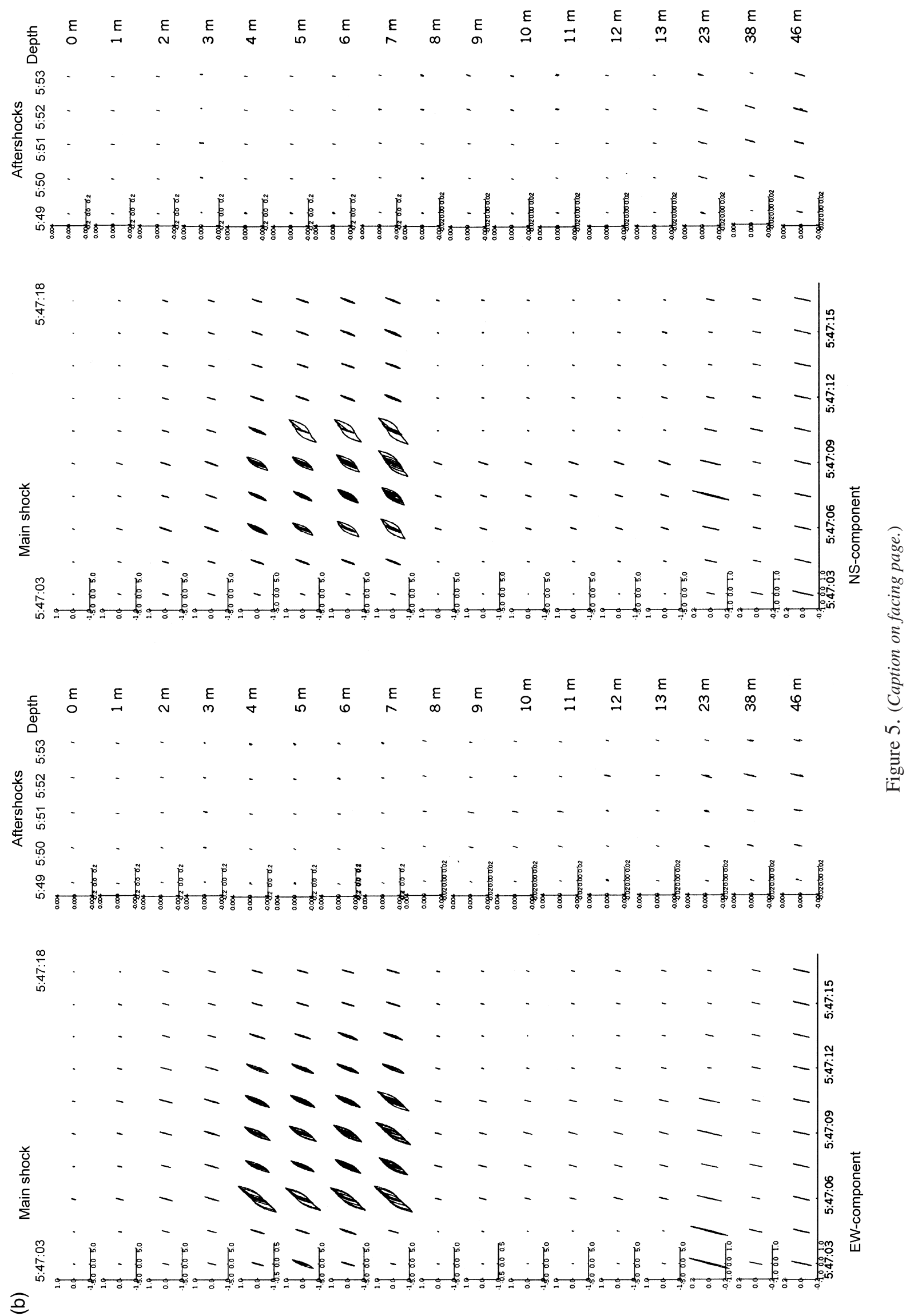

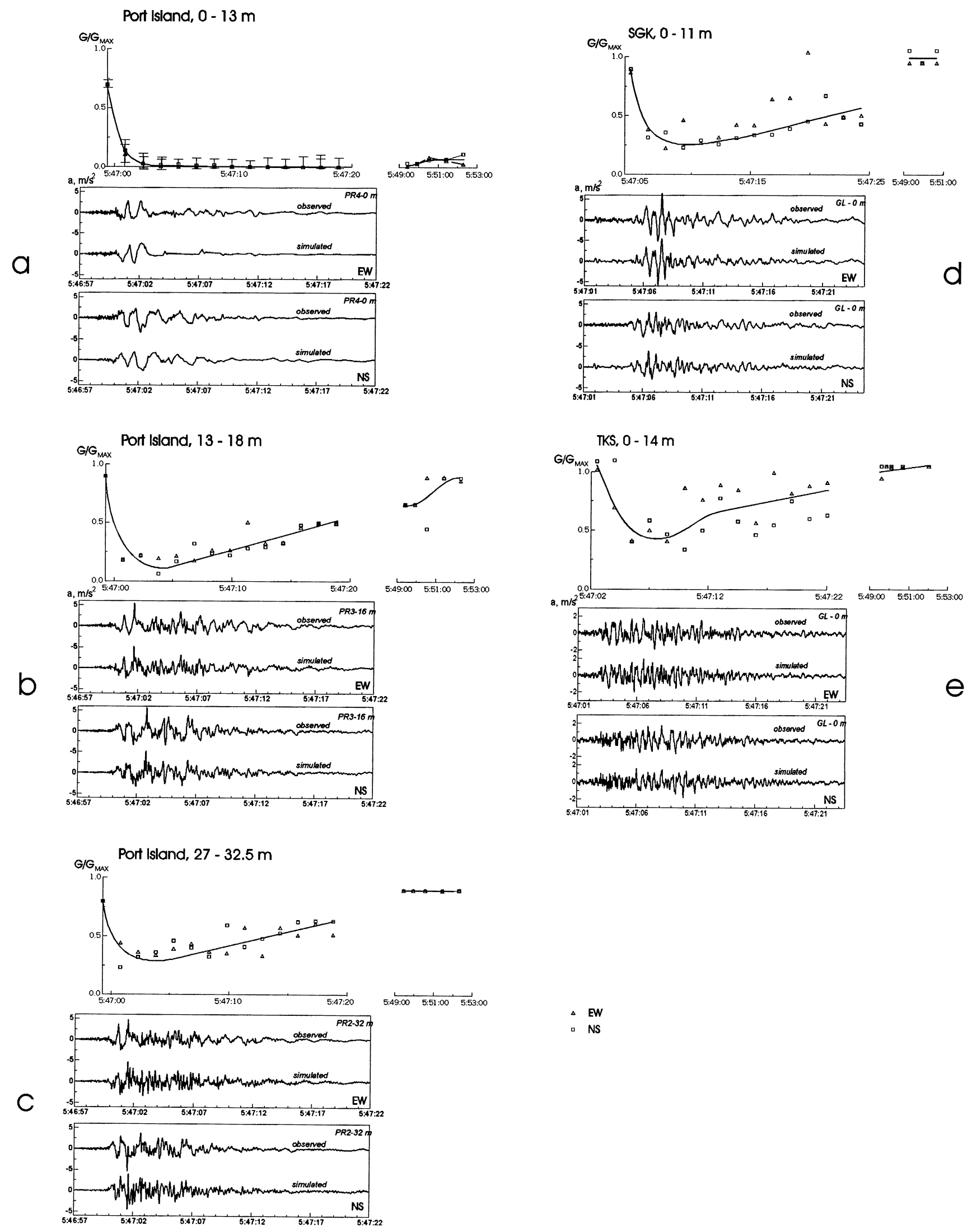

Figure 6. Shear-moduli evolution of subsurface soils at sites PI, SGK, and TKS during the 1995 Kobe earthquake and its aftershocks. 
$18 \mathrm{~m}$ was similar to that in the upper layers, but the soils were saturated with water (Fig. 1). According to our computations, a decrease in rigidity in these layers started with the beginning of strong motion and continued for 3-4 sec, that is, until the intensity of the imposed motion decreased. After that, compression and probably thixotropic strengthening took place. The maximum decrease of shear modulus was about $80 \%$, and the obtained stress-strain relations show its recovery during the following few minutes (Fig. 6b). The same tendency of shear-modulus changes can be revealed from stress-strain curves presented in Kazama et al. (1998), that is, its decrease during the first 1-4 sec of strong motion and the following recovery during the next $6-9 \mathrm{sec}$. If we average the obtained shear-modulus changes in 13-18 m, our results also agree with the results obtained in Sato et al. (1996), who identified an $80 \%$ and $50 \%$ reduction of $V_{s}$ for the saturated and unsaturated fill layers, respectively.

At depths of 27-32.5 m at PI, shear modulus decreased by $50 \%-60 \%$ of the initial value during the first few seconds of strong motion (Fig. 6c), which agrees on the whole with estimates made by Sato et al. (1996) that the optimized $V_{s}$ values for the total duration of the mainshock $(20 \mathrm{sec})$ were $\sim 20 \%$ and $40 \%$ smaller than the initial values obtained by the $P S$-wave logging test for the Pleistocene (gravel/clay, $50-83 \mathrm{~m}$ ) and Holocene (sand/clay, 20-50 m) layers, respectively.

\section{SGK and TKS Sites}

At site SGK, a shear modulus decrease was also observed in the upper layers, namely, $\sim 60 \%-70 \%$ of the initial value; recovery was completed during the following minutes. Figure $6 \mathrm{~d}$ shows the temporal changes of shear modulus in the upper 0-11 $\mathrm{m}$ at site SGK and the observed and simulated accelerograms of the mainshock on the surface. A sharp decrease in the rigidity of the upper layers at site SGK coincided with the beginning of strong motion, as at PI. Recovery began just after a decrease in the intensity of seismic motion and continued for a few minutes, until the shear modulus attained its final value. Soil conditions at PI and SGK were similar; therefore, the shear-modulus recovery at site SGK also included the soil compression accompanied by the loss of water and probably, the thixotropic strengthening of the structural coagulation lattice.

The role of thixotropic strengthening in the shear-modulus recovery at PI, SGK, and TKS sites is not clear. From one side, the recovery curves (Fig. 6a-6e) show some regularities of hardening, which are considered typical for weakly cohesive soils, such as the beginning of the recovery just after a decrease in the intensity of strong motion (Fig. $6 \mathrm{~b}, 6 \mathrm{c}, 6 \mathrm{~d}, 6 \mathrm{e})$, the nonuniformity of recovery during the first few minutes (Fig. 6a, 6b, 6d, 6e), and the rate and total time of the recovery. In the cases shown in Figure $6 \mathrm{~b}, 6 \mathrm{c}$, $6 \mathrm{~d}$, and 6e, recovery began just after a decrease in the intensity of strong motion. It is known that "instantaneous thixotropic strengthening" occurs just after termination of dynamic loading because the number of free particles taking part in the reconstruction of the structural lattice is maximum at that time. The highest increase in rigidity is observed during the first 3-10 minutes, and the presence of water accelerates this process because it increases the mobility of particles and their ability to reorient and establish the most energetically advantageous contacts (Voznesensky, 1999). Another peculiarity of some curves of the shear-modulus recovery is a disagreement between the initial and final values of rigidity (Fig. 6c, 6d). Soils do not possess an important property of thixotropic systems, such as the entire reversibility of the loss and recovery of their rigidity. Their final rigidity achieved after recovery is usually either less or higher than the initial one, depending on the inhomogeneity of a soil and the intensity of the preceding dynamic loading. Recovery of the rigidity in soils is related to phenomena aimed at ordering the system by decreasing its entropy, such as (1) increasing the energy of particle interaction, (2) destruction of structural bonds with low-level activation energy, (3) increasing the number of contacts between particles within a unit of volume (Voznesensky, 1999), and (4) redistribution of water to make it more uniform (Barber, 1958). These effects appear more clearly in cases of stronger dynamic loading, only in the first cycle of "destructionrecovery."

However, from the other side, we have neither the results of laboratory experiments, proving that "Masado" does bear thixotropic properties, nor any further evidence. The nonuniformity of the shear-moduli recovery and the disagreement between the initial and final values of the shear moduli can be the consequence of inaccuracies of the shear-moduli estimates. Therefore, in our case, thixotropic strengthening is only probable, although we cannot discard thixotropic mechanisms, because in weakly cohesive soils, consolidation is usually accompanied by thixotropic strengthening of the coagulation lattice, and the separation of compression and thixotropic effects is virtually impossible (Voznesensky, 1999).

Thus, our results confirm that the upper 10-13 $\mathrm{m}$ at PI and SGK are dynamically unstable systems. At the same time, the sensitivity of soils to dynamic loading obviously decreases with depth, and no changes were observed in deeper layers at sites PI and SGK. According to Voznesensky (1999), the largest decrease in rigidity was observed at the acceleration levels of $0.5-0.7 \mathrm{~g}$, and these values were attained at both PI and SGK sites. On the other hand, at site TKS, the highest measured accelerations were $\sim 0.2 g$, and the changes in soil rigidity of the upper layers were not so high. A single stress-strain relation was used to describe the soil behavior in the upper $0-14 \mathrm{~m}$ at site TKS, and changes in the shear modulus ( $\sim 50 \%$ of the initial value) were due to changes in the working areas of this stress-strain relation, depending on the intensity of the imposed motion (Fig. 6e). These changes occurred mostly in the upper meters below the water level, at 4-7 m depth (Fig. 5b).

Our estimates of the shear-modulus decrease at sites SGK and TKS differ from those obtained by Sato et al. 
(1996). They found that at site SGK the $V_{s}$ optimized for the total duration of the mainshock was $\sim 25 \%$ and $45 \%$ smaller than the initial value for the Pleistocene and Holocene layers, respectively. At site TKS, sand boils were observed after the quake, indicating that liquefaction took place at this site. The optimized $V_{s}$ was $\sim 10 \%$ and $30 \%$ smaller than the initial value for the Pleistocene and Holocene layers, respectively. The optimized velocity of the sand layer at a depth of $\sim 10$ $\mathrm{m}$ was reduced by $80 \%$ from the initial value, as in the liquefied-fill layer at PI (Sato et al., 1996). In contrast to their results, ours show stability in the shear moduli at depths below 11-14 $\mathrm{m}$ at sites SGK and TKS and no liquefaction at site TKS, yet liquefaction at TKS would be very probable for larger strains. Because the accuracy of the simulation in Sato et al. (1996) is not very high, as they themselves admit, and because their simulated records differ substantially from the observed ones, especially at a depth of $25 \mathrm{~m}$, we consider our estimates to be more exact.

Shear-moduli estimates at sites PI and SGK were obtained in a dynamic regime because of the presence of reverberated $S$ waves and basin-induced surface waves. These waves, representing standing waves in the Osaka basin, are noticeable at all depths at sites PI and SGK (Fig. 3a and 4a) and possess amplitudes of $0.03-0.06 \mathrm{~m} / \mathrm{sec}^{2}$ at a predominant frequency of $\sim 0.2 \mathrm{~Hz}$. The loading on soils created by these waves should be treated as dynamic, rather than quasistatic, because soil conditions are mostly undrained (Ishihara, 1998) when the soil permeability is not high enough for a complete dissipation of excess pore pressure during the phase of loading in each cycle. Dynamic loading on soils created by these waves is not large when compared with the mainshock, and most probably under this loading, soils came to a dynamic equilibrium characterized by a closed hysteretic loop.

\section{Conclusions}

The method of estimating nonlinear time-dependent stress-strain relations from vertical-array records, which has been described in Pavlenko and Irikura (2002a), was applied to study the changes of shear moduli in different layers at sites PI, SGK, and TKS during the 1995 Kobe earthquake and its first aftershocks.

Analysis of the aftershocks that occurred shortly after the mainshock, as well as of the mainshock itself, showed that the most noticeable changes in soil rigidity occurred in the upper layers at PI. The maximum decrease was observed to be $\sim 80 \%-90 \%$ in the upper reclaimed-fill layer $(0-18 \mathrm{~m})$ and $\sim 50 \%-60 \%$ in water-saturated sands at $27-32.5 \mathrm{~m}$. However, the shear-modulus recovery began 3-5 min after the decrease in the intensity of strong motion in the upper reclaimed layers above the level of underground water $(0$ $13 \mathrm{~m}$ ) and just after the decrease in the intensity of strong motion in the reclaimed fill below water level (13-18 m) and at depths of $27-32.5 \mathrm{~m}$.

At sites SGK and TKS, changes in the shear moduli occurred in the upper water-saturated alluvial and reclaimedsoil layers, $0-11 \mathrm{~m}$ and $0-14 \mathrm{~m}$, and reached $\sim 60 \%-70 \%$ and $\sim 50 \%$, respectively. At site SGK, shear-modulus recovery began after the decrease in intensity of the imposed motion and was completed in a few minutes. At site TKS, where recorded accelerations were substantially lower than at PI and SGK, no changes in the stress-strain relations were noticed, in contrast to sites PI and SGK. A single stressstrain relation can be used to describe the soil behavior in the upper layers at site TKS and the changes in soil rigidity were due to changes in the working areas of this curve, depending on the intensity of the imposed seismic motion.

Thus, soils in the upper layers at sites PI and SGK and sandy soils at depth at PI showed a dynamically unstable behavior during strong motion; that is, they changed their properties by decreasing their rigidity and increasing deformability. Soil behavior during the 1995 Kobe earthquake is a good illustration of the fact that soils are such natural multicomponent systems that they not only change the dynamic characteristics of propagating seismic waves but that they also change their own properties, and these processes are inseparable from each other.

The method of estimation of the stress-strain relations from vertical-array data show in detail soil behavior during strong motions and changes in the shear moduli in different layers during the mainshock and aftershocks. Such in situ observations represent a valuable complement to laboratory and field studies of soil properties.

Insofar as the method can be applied at any site where vertical-array records and profiling data are available, accumulation of representative data on nonlinear soil behavior under strong motion in different soil conditions is desirable. Summarizing and generalizing these data, we may become able to find the rational basis of how the model (the stressstrain curves) would change if the input changes in one or another site, that is, to predict soil behavior in future earthquakes.

\section{Acknowledgments}

We thank Yoshio Soeda, Hideki Tamai, and Naoyuki Nakatsu (Kansai Electric Power Company) for acceleration records of the vertical arrays at SGK and TKS recording sites. The acceleration records of the vertical array in PI were kindly provided by Kobe City. This study was partially supported by Special Coordination Funds of the Science and Technology Agency of the Japanese Government (PI: Kojiro Irikura).

\section{References}

Aguirre, J., and K. Irikura (1997). Nonlinearity, liquefaction, and velocity variation of soft soil Layers in PI, Kobe, during the Hyogo-ken Nanbu Earthquake, Bull. Seism. Soc. Am., 87, 1244-1258.

Akkerman, E. (1958). Thixotropy and fluidity of fine-grained soils, Prob. Eng. Geol., 1, 73-92.

Barber, E. S. (1958). Discussion on the paper 'Thixotropic characteristics of compacted clays' by Seed, H. B., and Chan, C. K. J. Soil Mech. Found. Div. 
Beresnev, I. A., and K.-L. Wen (1996). Nonlinear soil response-a reality? Bull. Seism. Soc. Am., 86, 1964-1978.

Boswell, P. G. H. (1949). A preliminary examination of the thixotropy of some sedimentary rocks, Q. J. Geol. Soc. London, 104, 499-526.

Casagrande, A. (1975). Liquefaction and cyclic deformation of sands: a critical review (lecture), 5th Panamerican Conference on Soil Mechanics and Foundation Engineering, Buenos Aires, 80-133.

Castro, G. (1975). Liquefaction and cyclic mobility of saturated sands, Proc. ASCE, 101, GT6, 551-569.

Dimitriu, P., N. Theodulidis, and P. Y. Bard (2000). Evidence of nonlinear site response in HVSR from SMART1 (Taiwan) data, Soil Dynam. Earthquake Eng. 20, 155-165.

Dimitriu, P., N. Theodulidis, P. Hatzidimitriou, and A. Anastasiadis (2001). Sediment non-linearity and attenuation of seismic waves: a study of accelerogramms from Lefkas, western Greece, Soil Dynam. Earthquake Eng. 21, 63-74.

Gumensky, B. M. (1965). Basis of physics and chemistry of clay soils and their use in civil engineering, Stroiizdat, Leningrad, Moscow, 255.

Hardin, B. O., and V. P. Drnevich (1972). Shear modulus and damping in soils: design equations and curves, Proc. Am. Soc. Civil Eng., J. Soil Mech. Found. Div., 98, 667-692.

Hatayama, K., K., Matsunami, T. Iwata, and K. Irikura (1995). Basininduced Love waves in the eastern part of the Osaka Basin, J. Phys. Earth, 43, 131-155.

Ishihara, K., F. Tatsuoka and S. Yasuda (1975). Undrained deformation and liquefaction of sand under cyclic stress, Soils Found. 15, 29-44.

Ishihara, K., M. Cubrinovski, and N. Takeshi (1998). Characterization of undrained behaviour of soils in the reclaimed area of Kobe, Soils Found. (special issue on geotechnical aspects of the January 171995 Hyogoken-Nambu earthquake), 2, 33-46.

Joyner, W. B., and T. F. Chen (1975). Calculation of nonlinear ground response in earthquakes, Bull. Seism. Soc. Am., 65, 1315-1336.

Kazama, M., A. Yamaguchi, and E. Yanagisawa (1998). Seismic behavior of an underlying alluvial clay on man-made islands during the Hyogoken-Nanbu earthquake, Soils Found. (special issue on geotechnical aspects of the January 171995 Hyogoken-Nambu earthquake), 2, 23-32.

Kokusho, T., and M. Matsumoto (1998). Nonlinearity in site amplification and soil properties during the 1995 Hyogoken-Nambu earthquake, Soils Found. (special issue on geotechnical aspects of the January 17 1995 Hyogoken-Nambu earthquake), 2, 1-9.

Kramer, S. L. (1996). Geotechnical Earthquake Engineering, Upper Saddle River, Prentice Hall, NJ, 230-238.

Lee, K. L. (1976). Influence of end restraint in cyclic triaxial tests. WES CR S-76-1, USAE Waterways Experiment Station, Corps of Engineers, Vicksburg, MS.

Pavlenko, O. V., and K. Irikura (2002a). Estimation of nonlinear time- dependent soil behavior in strong ground motions based on vertical array data, Pageoph (in press).

Pavlenko, O. V., and K. Irikura (2001b). Types of elastic nonlinearity of sedimentary soils, Geophys. Res. Lett., (in press).

Pitarka, A., K. Irikura, T. Iwata, and H. Sekiguchi (1998). Three-dimensional simulation of the near-fault ground motion for the 1995 Hyogoken Nanbu (Kobe), Japan, earthquake, Bull. Seism. Soc. Am., 88, $428-440$.

Sato, K., T. Kokusho, M. Matsumoto, and E. Yamada (1996). Nonlinear seismic response and soil property during 1995 Hyogoken Nanbu earthquake, Soils Found. (special issue on geotechnical aspects of the January 17, 1995 Hyogoken Nanbu earthquake), 2, 41-52.

Seed, H. B., and K. L. Lee (1966). Liquefaction of saturated sands during cyclic loading, J. Soil Mech. Found. Div. 92, 105-134.

Seed, H. B., R. T. Wong, I. M. Idriss, and K. Tokimatsu (1984). Moduli and damping factors for dynamic analyses of cohesionless soils, Report No. UCB/EERC-84/14, September.

Soeda, Y., H. Tamai, N. Nakatsu, K. Takezawa, and F. Maegawa (1999). Nonlinearity and irregularity of strong seismic motions by vertical arrays during the 1995 Kobe earthquake, in Earthquake Geotechnical Engineering, Seco e Pinto ed., Balkema, Rotterdam, 225-230.

Sun, J. I., R. Golesorkhi, and H. B. Seed (1988). Dynamic moduli and damping ratios for cohesive soils, Report No. UCB/EERC-88/15, August.

Voznesensky, E. A. (1994). Dynamic instability of soils and rocks, in Proceedings of the 7th International IAEG Congress, Lisboa, A. A. Balkema, Rotterdam, Brookfield, 683-692.

Voznesensky, E. A. (1999). Dynamic instability of soils, Editorial UPSS, Moscow, 264.

Yasuda, S., K. Ishihara, K. Harada, and N. Shinkawa (1996). Effect of soil improvement on ground subsidence due to liquefaction, Soils Found. (special issue on geotechnical aspects of the January 171995 Hyogoken-Nambu earthquake), 2, 99-107.

Zvolinsky, N. V. (1982). Wave processes in non-elastic media, Probl. Eng. Seism. 23, 4-19.

Institute of Physics of the Earth

Russian Academy of Sciences,

Moscow Russia

(U.P.)

Disaster Prevention Research Institute

Kyoto University,

Kyoto, Japan

(K.T.)

Manuscript received 26 March 2001. 